CAHIER DE RECHERCHE \#1210E

Département de science économique

Faculté des sciences sociales

Université d'Ottawa
WORKING PAPER \#1210E

Department of Economics

Faculty of Social Sciences

University of Ottawa

\title{
Emissions Cap or Emissions Tax? A Multi-sector Business Cycle Analysis
}

\author{
Yazid Dissou and Lilia Karnizova*
}

August 2012

\footnotetext{
* Department of Economics, University of Ottawa, 120 University Street, Ottawa, Ontario, Canada, K1N 6N5. Email addresses: Yazid.Dissou@uOttawa.ca, Lilia.Karnizova@uOttawa.ca.

The authors thank Qian Sun for excellent research assistance. Yazid Dissou acknowledges financial support from a grant on Canadian environmental issues by the Canadian Social Sciences and Humanities Research Council (SSHRC).
} 


\begin{abstract}
In contrast to previous studies, this paper uses a multi-sector setting to assess aggregate and sectoral impacts of reducing carbon dioxide emissions in the presence of stochastic productivity shocks. We develop a multi-sector dynamic stochastic general equilibrium model, calibrated to the U.S. economy, to compare the economic implications of reducing carbon emissions with an emissions cap and with an emission tax. As in previous studies, we find that an emission cap predicts lower volatility of aggregate variables than an emission tax. Still, our results point to the importance of going beyond a single-sector analysis in evaluating the relative merits of the cap and the tax policies. The ranking of the welfare costs under the two regimes depends on the sources of productivity shocks. While there is no difference in the welfare costs of the two regimes for productivity shocks originating from non-energy sectors, we find that an emissions cap policy is more costly than an emission tax policy for shocks that originate from the energy sectors. Moreover, we find that non-energy shocks have distinct sectoral impacts under the two regimes even though there are no significant differences between the two regimes for the aggregate variables.
\end{abstract}

Key words: cap-and-trade; carbon tax; emissions; business cycle; multiple sectors JEL Classification: E32, Q43, Q54, Q58

\title{
Résumé
}

Contrairement aux études précédentes, cet article utilise un cadre multisectoriel pour évaluer les impacts agrégés et sectoriels de la réduction des émissions de dioxyde de carbone en présence de chocs de productivité stochastiques. Nous développons un modèle multisectoriel stochastique d'équilibre général dynamique, calibré sur l'économie des États-Unis, pour comparer les conséquences économiques de la réduction des émissions de carbone en utilisant un plafond d'émissions et une taxe sur les émissions. À l'instar des précédentes études, nous trouvons que la volatilité des variables agrégées est plus faible avec le plafond sur les émissions. Toutefois, nos résultats soulignent l'importance d'aller au-delà d'un modèle à un seul secteur pour évaluer les impacts économiques du plafond sur les émissions et d'une taxe sur les émissions. Le classement des coûts en bien-être des deux régimes dépend de la source des chocs de productivité. Bien qu'il n'y ait aucune différence dans les coûts de bien-être des deux régimes pour les chocs de productivité provenant des industries non-énergétiques, nous notons que le plafonnement des émissions est plus coûteux que la taxe sur les émissions lorsque les chocs proviennent des secteurs de l'énergie. En outre, nous notons que les chocs provenant des secteurs nonénergétiques ont des impacts sectoriels distincts pour les deux régimes, quand bien même il n'y a pas de différences significatives entre les deux régimes au niveau des impacts sur les variables agrégées.

Mots clés: un plafond d'émissions ; une taxe sur les émissions ; les émissions ; le cycle économique ; un modèle multisectoriel

Classification JEL: E32, Q43, Q54, Q58 


\section{Introduction}

Current concentrations of carbon dioxide $\left(\mathrm{CO}_{2}\right)$, the dominant greenhouse gas, are alarmingly large. The scientific community agrees on their harmful effects on climate change and calls for an immediate reduction of emissions. Two main market-based approaches to control carbon emissions are a cap-and-trade system of marketable permits ( Cap) and a carbon $\operatorname{tax}(\operatorname{Tax})$. The cap and the tax policies are simple and relatively easy to implement and manage. $\quad$ Various forms of these two policies are already in effect in several jurisdictions. ${ }^{1}$ Yet, a consensus has not been reached on which policy works best (Metcalf, 2009). The present study contributes to the debate by examining the performance of the cap and the tax in the presence of macroeconomic uncertainty.

Accounting for macroeconomic uncertainty is important for two reasons. First, uncertainty leads to volatile consumption, which is costly to risk-averse individuals. The cost of consumption fluctuations should be made explicit in the cost-and-benefit analysis of the emissions policy. Second, it is known from the work of Weitzman (1974) that quantitybased and price-based regulations may not be equivalent from the welfare perspective in an uncertain environment. A cap policy is a quantity-based system. It fixes the quantity of emissions, and leaves the market to determine the permit price. By contrast, a carbon tax is a price-based system. It fixes the price of carbon and lets the market determine the equilibrium quantity of emissions.

Only two existing studies analyze the emissions policy in the presence of macroeconomic uncertainty. In both studies, the uncertainty comes from stochastic changes in aggregate total factor productivity (TFP). Fischer and Springborn (2011), denoted by FS (2011) hereafter, compare the cap, the tax and the intensity target in a dynamic stochastic general

\footnotetext{
${ }^{1}$ The European Union's Emissions Trading Scheme and the Regional Greenhouse Gas Initiative program in the U.S. are just two examples of a cap system. Carbon taxes have been in place in a number of the Scandinavian countries since the early 1990s. In 2008, carbon taxes were implemented in the provinces of Quebec and British Columbia in Canada. Metcalf (2009) provides details on these and other programs.
} 
equilibrium (DSGE) model with one polluting intermediate input. The cap in their model reduces economic volatility relative to all other regimes. However, the tax policy has the lowest welfare costs when the transitional adjustment to the emissions regulation is taken into account. Heutel (2012) determines an optimal emissions policy in a DSGE model with a pollution externality. While the optimal policy can be implemented with either a cap or a tax, the tax regulation has a political advantage. The cap policy should be strengthened during recessions By contrast, the tax policy should be weakened, which could be more politically feasible.

The previous work has two important limitations. First, aggregate productivity shocks are the only source of uncertainty. Carbon emissions are mostly related to the use of energy. It is not clear whether TFP shocks originating in energy-producing sectors would have the same impacts as TFP shocks from other sectors. Second, the analysis is restricted to a single sector framework. Impacts of productivity shocks need not be identical for all sectors under the two policy regimes. The main objective of the present study is to compare the cap and the tax policies in a stochastic environment when both limitations are relaxed.

We construct a DSGE model with heterogenous production sectors and sectoral productivity shocks. Firms in different sectors vary in their capacity to substitute between primary and intermediate inputs, including three types of energy: electricity, coal, and oil and gas. Carbon emissions are generated by fossil fuel combustion. Burning of coal releases more $\mathrm{CO}_{2}$ than burning of oil and gas. The use of electricity does not produce emissions. The emissions policy in the model aims to control the total level of emissions. Since there is a constant relationship between the use of each fossil fuel and carbon emissions, controlling the level of emissions amounts to controlling the use of energy. The latter is achieved through the price system. The emissions policy increases the price of fossil fuels, either by imposing a carbon tax or by requiring the purchase of emissions rights before using fossil fuels.

The model is calibrated to the actual input-output structure of the U.S. economy, and 
solved numerically. The model is used to answer the following questions: "How does a model economy respond to different TFP shocks under the cap and the tax policies? Are there any systematic differences in volatility of aggregate variables and welfare measures by the origin of the productivity shocks? Are there sectoral differences in responses to the same types of shocks?" To the best of our knowledge, there is no comparable study that evaluates the environmental regulation in a multi-sector business cycle model.

Our results point to the importance of going beyond a single sector, one aggregate productivity shock specification in evaluating the relative merits of the cap and the tax policies. Of a particular interest is the behavior of the fossil fuel sectors. The emissions policy in the model works through the pricing mechanisms by increasing the user prices of fossil fuels and changing their relative prices. These price changes trigger a series input substitution and price effects that vary across the sectors.

Empirical studies of industry-level impacts of oil price shocks in the U.S. provide support for the transmission mechanisms of our multi-sector model. First, oil price shocks act mostly like the supply shocks in oil-intenstive industries, but like the demand shocks for many other industries (Lee and Ni, 2002). Second, oil price shocks cause a significant job reallocation in the U.S. economy. The magnitude of employment responses varies systematically with sectoral characteristics such as capital intensity, energy intensity and product durability (Davis and Haltiwanger, 2001) Finally, input-output linkages across sectors are found important in amplifying the effects of oil price shocks (Linn, 2009).

The rest of the paper is organized as follows. Section 2 outlines the model. Section 3 describes the parameter calibration, the solution and simulations. Section 4 analyzes the effects of the emission policy in the absence of productivity shocks. Section 5 first examines the business cycle implications of the model with no emissions policy. Then it evaluates the effects of the cap and the tax policies in a stochastic environment. Section 7 concludes. 


\section{The model}

The economy consists of identical infinitely lived households, a government and $N$ distinct production sectors. Four elements are central to the model: (i) an explicit specification of the energy production; (ii) imperfect substitutability of coal, oil and gas, and electricity as production inputs; (iii) sectoral productivity shocks and (iv) an environmental policy with respect to emissions control. Households are the owners of the physical capital stock, make investment decisions and rent physical capital to the firms. Moreover, the labor supplied by households is imperfectly mobile across sectors. The model is presented as the decentralized competitive equilibrium. $^{2}$ This section first describes the equilibrium in the absence of regulations. It then explains how the equilibrium is modified by an emissions policy.

\subsection{Production sectors}

There are six sectors, each producing a distinct commodity. For notational simplicity, both the sectors and the commodities are indexed by the same index $j$. Three sectors produce energy: coal (COAL), oil and gas (OIL), and electricity (ELEC). The other three sectors produce energy-intensive and energy non-intensive goods (EIN and NIEN), and provide services (SERV). In addition to the general index $j$, the sectors are also referred by their abbreviated names. All production sectors are perfectly competitive. Without loss of generality, we focus on the decisions of a representative firm in each sector.

The representative firm in sector $j$ operates constant returns to scale production technology that uses capital $K_{j t}$, labor $L_{j t}$ and intermediate inputs $M_{j t}^{i}(i=1, \ldots, N)$. The notation $M_{j t}^{i}$ indicates how much of the good produced in sector $i$ is used by sector $j$. The firm rents capital from the households at the rental rate $R_{t}$ per unit of capital, and buys labor at the hourly wage rate $w_{j t}$. All the intermediate goods are delivered within the period. Output

\footnotetext{
${ }^{2}$ The competitive equilibrium is not Pareto optimal, since the model features several distortionary taxes.
} 
$Y_{j t}$ of good $j$ in period $t$ is produced according to

$$
Y_{j t}=F\left(K L E\left\{A_{j t}, K_{j t}, L_{j t}, E\left[F S\left(M_{j t}^{\text {coal }}, M_{j t}^{\text {oil }}\right), M_{j t}^{\text {elec }}\right]\right\}, M_{j t}^{\text {ein }}, M_{j t}^{\text {nein }}, M_{j t}^{\text {serv }}\right) .
$$

The production function $F$ is weakly separable in several inputs, and provides various substitution possibilities. Gross output is a Leontief composite of a $K L E$ aggregator of capital, labor and energy inputs, and of non-energy intermediate inputs,

$$
Y_{j t}=\min \left\{\frac{1}{a_{j}^{k l e}} K L E_{j t}, \frac{M_{j t}^{\text {ein }}}{a_{j}^{\text {ein }}}, \frac{M_{j t}^{\text {nein }}}{a_{j}^{\text {nein }}}, \frac{M_{j t}^{\text {serv }}}{a_{j}^{\text {serv }}}\right\}
$$

with the weights $a_{j}^{i}>0$. The $K L E_{j t}$ index is a Cobb-Douglas function of capital, labor and energy $E_{j t}$, with the capital and labor shares $\alpha_{K j}, \alpha_{L j} \in(0,1)$,

$$
K L E_{j t}=K L E\left(A_{j t}, K_{j t}, L_{j t}, E_{j t}\right)=A_{j t} K_{j t}^{\alpha_{K j}} L_{j t}^{\alpha_{L j}} E_{j t}^{1-\alpha_{K j}-\alpha_{L j}}
$$

The value of $A_{j t}$ represents the total factor productivity in sector $j$, with $A_{j t}=\bar{A}_{j} Z_{j t}$. The scale factor $\bar{A}_{j}>0$. Similar to Horvath (2000) and Kim and Kim (2006), the productivity shock $Z_{j t}$ follows a stochastic process described by

$$
\ln Z_{j t}=\rho_{j} \ln Z_{j, t-1}+\varepsilon_{j t}, \rho_{j} \in(0,1)
$$

The innovations $\varepsilon_{j t}$ are serially uncorrelated and normally distributed random variables with zero mean and $E\left(\varepsilon_{t} \varepsilon_{t}^{\prime}\right)=\Omega$. While the productivity shocks $Z_{j t}$ are sector-specific, they are not necessarily mutually independent. The variance-covariance matrix $\Omega$ is therefore not restricted to be diagonal. Since in equilibrium, $Y_{j t}=K L E_{j t} / a_{j}^{k l e}$, the productivity shock $Z_{j t}$ is also a TFP shock. We abstract from productivity growth in order to focus on business cycle implications of the carbon controls. Our model, however, can be interpreted as a stationary (detrended) representation of another model that includes sector-specific 
productivity trends.

The index of the energy input is a constant elasticity of substitution (CES) aggregate of electricity and the fossil energy index, with the elasticity of substitution $\sigma_{E j}>0$. The fossil energy itself is a CES combination of coal, and oil and gas intermediate inputs, with the elasticity of substitution $\sigma_{F j}>0$. In particular,

$$
\begin{aligned}
E_{j t} & =E\left(F S_{j t}, M_{j t}^{\text {elec }}\right)=A_{j}^{E}\left[a_{E j}\left(F S_{j t}\right)^{\frac{\sigma_{E j}-1}{\sigma_{E j}}}+\left(1-a_{E j}\right)\left(M_{j t}^{\text {elec }}\right)^{\frac{\sigma_{E j}-1}{\sigma_{E j}}}\right]^{\frac{\sigma_{E j}}{\sigma_{E j}-1}}, \\
F S_{j t} & =F S\left(M_{j t}^{c o a l}, M_{j t}^{o i l}\right)=A_{j}^{F}\left[a_{F j}\left(M_{j t}^{c o a l}\right)^{\frac{\sigma_{F j}-1}{\sigma_{F j}}}+\left(1-a_{F j}\right)\left(M_{j t}^{o i l}\right)^{\frac{\sigma_{F j}-1}{\sigma_{F j}}}\right]^{\frac{\sigma_{F j}}{\sigma_{F j}-1}},
\end{aligned}
$$

where the scale parameters $A_{j}^{E}>0, A_{j}^{F}>0$ and the weights $a_{E j} \in(0,1), a_{F j} \in(0,1)$. When $a_{F j}=0$, coal is not used as an intermediate input in the production process for good $j$, and hence $M_{j t}^{\text {coal }}=0$. This is the case for services in our empirical analysis. The specifications (4)-(5) provide a flexible representation of the substitution possibilities available to the firms in terms of the sources of energy. This choice becomes especially relevant in the presence of emissions controls. Coal, oil and gas are polluting inputs, with a different degree of emissions intensities. The use of these inputs will be subject to environmental regulation. By contrast, the use of electricity will not be regulated.

As the capital stock is owned by the households, the representative firm's optimization problem is static. In every period $t$ the firm chooses the quantity of production factors to maximize its profits

$$
\max P_{j t}^{y} Y_{j t}-R_{t} K_{j t}-w_{j t} L_{j t}-\sum_{i=1}^{N} p_{i t} M_{j t}^{i},
$$

subject to the definitions $(1)-(5)$ and taking input and output prices as given. $P_{j t}^{y}$ is the producer price, and $p_{i t}$ is the user price of the intermediate input $i$ used by the firm in sector $j$. There is a difference between the producer and user prices. A producer tax $\tau_{j} \in(0,1)$ creates a wedge between the two prices: $P_{j t}^{y}=\left(1-\tau_{j}\right) p_{j t}$.

Profit maximization leads to the usual optimal conditions such that each factor is em- 
ployed up to the point where its marginal product is equal to its price. A discussion of the optimal conditions is nevertheless warranted because of the relatively complex specification of technology. In what follows, we use cost minimization principles to determine the optimal input levels. Note that cost minimization is equivalent to profit maximization for the linearly homogeneous technology. Moreover, the weak separability of the production function allows sequential decision making by the firm: the firm can first determine the optimal level of the composite inputs and then find the optimal levels of its components. We use the marginal cost pricing rule and derive the conditional demand for each input. The exact expressions for prices and input demands should help the reader get a good grasp of the mechanisms through which the carbon control policy will affect the firm's decisions.

The optimal conditions related to the firm's problem are as follows. The marginal cost of producing good $j$ is

$$
P_{j t}^{y}=a_{j}^{k l e} P_{j t}^{k l e}+a_{j}^{e i n} M_{j t}^{e i n}+a_{j}^{n e i n} M_{j t}^{n e i n}+a_{j}^{s e r v} M_{j t}^{s e r v}
$$

The demand for the KLE composite and the non-energy intermediate inputs are

$$
\begin{aligned}
K L E_{j t} & =a_{j}^{k l e} Y_{j t} \\
M_{j t}^{i} & =a_{j}^{i} Y_{j t}, i \in\{e i n, \text { nein, serv }\}
\end{aligned}
$$

In order to simplify the analytical expressions, we introduce three auxiliary price indices $P_{j t}^{k l e}, P_{j t}^{e}$ and $P_{j t}^{f s}$ that correspond to the $K L E$ index, the total use of energy and the fossil fuels by sector $j$. The price index $P_{j t}^{k l e}$ is defined as

$$
P_{j t}^{k l e}=\frac{1}{A_{j t}}\left[\frac{R_{t}}{\alpha_{K j}}\right]^{\alpha_{K j}}\left[\frac{w_{j t}}{\alpha_{L j}}\right]^{\alpha_{L j}}\left[\frac{P_{j t}^{e}}{1-\alpha_{K j}-\alpha_{L j}}\right]^{1-\alpha_{K j}-\alpha_{L j}} .
$$


The demands for capital, labor and energy inputs for sector $j$ are

$$
\begin{aligned}
K_{j t} & =\alpha_{K j} K L E_{j t}\left[P_{j t}^{k l e} / R_{t}\right], \\
L_{j t} & =\alpha_{L j} K L E_{j t}\left[P_{j t}^{k l e} / w_{j t}\right], \\
E_{j t} & =\left(1-\alpha_{K j}-\alpha_{L j}\right) K L E_{j t}\left[P_{j t}^{k l e} / P_{j t}^{e}\right] .
\end{aligned}
$$

The expressions for the energy price index and the demand for the index of fossil fuels, $F S_{j t}$, and electricity $M_{j t}^{\text {elec }}$ by sector $j$ are

$$
\begin{aligned}
P_{j t}^{e} & =\frac{1}{A_{j}^{E}}\left[\left(\alpha_{E_{j}}\right)^{\sigma_{E j}}\left(P_{j t}^{f s}\right)^{1-\sigma_{E j}}+\left(1-\alpha_{E_{j}}\right)^{\sigma_{E j}}\left(p_{\text {elec }, t}\right)^{1-\sigma_{E j}}\right]^{1 /\left(1-\sigma_{E j}\right)}, \\
F S_{j t} & =\left(A_{j}^{E}\right)^{\sigma_{E j}-1}\left(\alpha_{F_{j}}\right)^{\sigma_{E j}} E_{j t}\left[P_{j t}^{e} / P_{j t}^{f s}\right]^{\sigma_{E j}}, \\
M_{j t}^{\text {elec }} & =\left(A_{j}^{E}\right)^{\sigma_{E j}-1}\left(1-\alpha_{F_{j}}\right)^{\sigma_{E j}} E_{j t}\left[P_{j t}^{e} / p_{\text {elec }, t}\right]^{\sigma_{E j}} .
\end{aligned}
$$

The index price of fossil fuels depends on the user prices of coal, and oil and gas:

$$
P_{j t}^{f s}=\frac{1}{A_{j}^{F}}\left[\left(a_{F j}\right)^{\sigma_{F_{j}}}\left(p_{\text {coal }, t}\right)^{\left(1-\sigma_{F_{j}}\right)}+\left(1-a_{F j}\right)^{\sigma_{F_{j}}}\left(p_{\text {oil }, t}\right)^{\left(1-\sigma_{F j}\right)}\right]^{1 /\left(1-\sigma_{F j}\right)} .
$$

Finally, the demand for each individual fossil fuel, that is for coal, and oil and gas is

$$
\begin{aligned}
M_{j t}^{\text {coal }} & =\left(A_{j}^{F}\right)^{\sigma_{F j}-1}\left(a_{F j}\right)^{\sigma_{F_{j}}} F S_{j t}\left[P_{j t}^{f s} / p_{\text {coal }, t}\right]^{\sigma_{F_{j}}}, \\
M_{j t}^{o i l} & =\left(A_{j}^{F}\right)^{\sigma_{F j}-1}\left(1-a_{F j}\right)^{\sigma_{F_{j}}} F S_{j t}\left[P_{j t}^{f s} / p_{o i l, t}\right]^{\sigma_{F_{j}}} .
\end{aligned}
$$

The relative demand for the fossil fuels depends on the relative user prices at which firms buy these intermediate inputs. A change in the relative price $p_{c o a l, t} / p_{\text {oil }, t}$ will trigger a series of cascading input substitution and price effects that will ultimately affect the marginal cost of the firm. Consider, for example, an increase in the user price of coal. Such increase will raise the demand for oil and gas relative to the demand for coal in each sector $j$. The resulting demand shift will change the composition of the index of fossil fuels $F S_{j t}$ and its 
price index $P_{j t}^{f s}$. The latter price change will modify the relative price of electricity and the aggregate of fossil fuels, which, in turn, will affect the ratio of the quantities of these two inputs in the index of total energy $E_{j t}$, and will also change the index price of total energy $P_{j t}^{e}$. The process will continue and eventually change the marginal cost of production of the firm defined in (6).

The magnitudes of the cascading input substitution and price effects will depend on two factors: the ease of substitution among inputs and their relative shares in production functions. An index price will react stronger to the increase in the relative price of one of its components when this component has a low substitutability or when it is more important in production (i.e. its share is larger). It follows that the marginal cost of production will be more sensitive to the increase in energy prices in the sectors with larger energy intensity. Further, the change of the user price of energy will affect not only energy producers, but also all other sectors of the economy.

The emissions policy will work through increasing the user prices of the fossil fuels. An introduction of the policy will trigger a change in the relative prices of coal, and oil and gas. This change will directly increase the production costs of all the sectors through the mechanisms outlined above. It is worth noting that the cascading effects will be compounding if an energy producing sector will also happen to be energy intensive. In this case, the higher user price of energy will embed not only the direct effects of the regulation, but also the increased production costs of the energy producing sector that is energy intensive.

\subsection{Households}

The representative household maximizes the expected utility

$$
E_{0} \sum_{t=0}^{\infty} \beta^{t}\left[\ln C_{t}+\chi \ln \left(1-H_{t}\right)\right], \beta \in(0,1), \chi>0
$$

where $\beta$ is the discount factor, $C_{t}$ is aggregate consumption, $H_{t}$ is aggregate hours worked. 
The population size is constant and normalized to one. Consumption is a Cobb-Douglas aggregate over the subset $N_{c}$ of all available $N$ goods,

$$
C_{t}=A_{c} \prod_{j \in N_{c}}\left(c_{j t}\right)^{\xi_{j}}, A_{c}>0, \xi_{j} \in(0,1), \sum_{j \in N_{c}} \xi_{j}=1
$$

The household consumes $c_{j t} \geq 0$ goods produced in sector $j$ in period $t$. For $j \notin N_{c}$, good $j$ is not used for consumption, hence $c_{j t}=0$. The scale parameter $A_{c}$ as well as the parameters $A_{h}$ and $A_{x}$ defined below are included in the aggregators to normalize the values of the individual and aggregate prices to unity in the steady state.

The household is endowed with one unit of time in each period $t$. Time is allocated between leisure and work, and $1-H_{t}$ represents leisure. The household has preferences for diversity of labor. The aggregate labor supply is a constant elasticity of transformation aggregate of hours $h_{j t}$ supplied to each sector $j$, with the elasticity $\zeta>0$ :

$$
H_{t}=A_{h}\left[\sum_{j=1}^{N} \eta_{j} h_{j t}^{(\zeta+1) / \zeta}\right]^{\zeta /(\zeta+1)}, A_{h}>0, \eta_{j} \in(0,1), \sum_{j=1}^{N} \eta_{j}=1
$$

If labor hours are perfect substitutes across the sectors $(\zeta=\infty)$, all sectors pay the same hourly wage. The aggregator (12) is motivated by the existence of sector specificity of labor and cross-sectional heterogeneity of wages (Horvath, 2000 and Bouakez at el., 2009). This specification implicitly restricts labor mobility and captures imperfect substitutability of labor across the sectors within the representative agent framework.

The household owns the stock of capital $K_{t}$. The initial stock of capital $K_{0}>0$ is given. Capital is accumulated through an investment process according to

$$
K_{t+1}=(1-\delta) K_{t}+X_{t}, t \geq 0
$$

where $\delta \in(0,1)$ is the rate of capital depreciation. The composite investment good $X_{t}$ is 
created by combining the subset $N_{x}$ of all available $N$ goods,

$$
X_{t}=A_{x} \prod_{j \in N_{x}}\left(x_{j t}\right)^{\gamma_{j}}, A_{x}>0, \gamma_{j} \in(0,1), \sum_{j \in N_{x}} \gamma_{j}=1
$$

For $j \notin N_{x}$, the quantity of good produced in sector $j$ is not purchased by the household for investment purposes, hence $x_{j t}=0$.

The household has three sources of income: wage income, capital income and lumpsum government transfers $T_{t}$. Both labor and capital income are subject to taxes, where $\tau_{h}, \tau_{k} \in(0,1)$ denote the tax rates. We assume that the household pays the same user price $p_{j t}$ for good $j$, irrespective of whether this good is bought for consumption or investment purposes. The household's budget constraint in period $t$ is

$$
\sum_{j=1}^{N} p_{j t} c_{j t}+\sum_{j=1}^{N} p_{j t} x_{j t}=\left(1-\tau_{h}\right) \sum_{j=1}^{N} w_{j t} h_{j t}+\left(1-\tau_{k}\right) R_{t} K_{t}+T_{t} .
$$

The household chooses the sequences $\left\{c_{j t}, h_{j t}, x_{j t}\right\}_{t=0}^{\infty}$ for every good $j=1, \ldots, N$ to maximize the utility (10), subject to the budget constraints (15), the capital accumulation equation (13), the definition of consumption, hours and investment aggregate indices (11), (12) and (14), a no-Ponzi game condition, and the initial stock of capital. The first-order optimality conditions for the household's problem determine the consumption and investment demand for the good produced in sector $j$,

$$
\begin{aligned}
c_{j t} & =\xi_{j} \frac{P_{t} C_{t}}{p_{j t}} \text { for } j \in N_{c}, c_{j t}=0 \text { for } j \notin N_{c}, \\
x_{j t} & =\gamma_{j} \frac{Q_{t} X_{t}}{p_{j t}} \text { for } j \in N_{x}, x_{j t}=0 \text { for } j \notin N_{x},
\end{aligned}
$$

where $P_{t}=\frac{1}{A_{c}} \Pi_{j \in N_{c}}\left(\frac{p_{j t}}{\xi_{j}}\right)^{\xi_{j}}$ and $Q_{t}=\frac{1}{A_{x}} \Pi_{j \in N_{x}}\left(\frac{p_{j t}}{\gamma_{j}}\right)^{\gamma_{j}}$ are aggregate consumption and investment price indices. Generally $P_{t} \neq Q_{t}$, even though $c_{j t}$ and $x_{j t}$ have the same user 
price $p_{j t}$. Labor supply for sector $j$ is given by

$$
h_{j t}=\frac{1}{A_{h}^{1+\zeta}}\left(\frac{w_{j t}}{\eta_{j} W_{t}}\right)^{\zeta} H_{t}
$$

where $W_{t}=\frac{1}{A_{h}}\left[\Sigma_{j=1}^{N}\left(\eta_{j}\right)^{-\zeta}\left(w_{j t}\right)^{1+\zeta}\right]^{1 /(1+\zeta)}$ defines the aggregate wage. Consumption, investment and wage indices have the properties that $\Sigma_{j=1}^{N} p_{j t} c_{j t}=P_{t} C_{t}, \Sigma_{j=1}^{N} p_{j t} x_{j t}=Q_{t} X_{t}$ and $\Sigma_{j=1}^{N} w_{j t} h_{j t}=W_{t} H_{t}$.

At the optimum, hours supplied to sector $j$ equate the marginal rate of substitution between consumption and leisure to the sectoral wage. The Technical Appendix shows that $C_{t}$ and $H_{t}$ satisfy two optimality conditions for $t \geq 0$ :

$$
\begin{aligned}
\frac{\chi C_{t}}{1-H_{t}} & =\left(1-\tau_{h}\right) \frac{W_{t}}{P_{t}} \\
\frac{1}{C_{t}} & =\beta E_{t}\left[\frac{1}{C_{t+1}} \frac{\left[\left(1-\tau_{k}\right) R_{t+1}+(1-\delta) Q_{t+1}\right] / P_{t+1}}{Q_{t} / P_{t}}\right] .
\end{aligned}
$$

The first equation equates the marginal rate of substitution between consumption and leisure to the market price of leisure, which is the after tax real wage. The second equation describes a trade-off between consumption and saving. The second term in the brackets represents the real rate of return on capital, the only asset in the model.

\subsection{The government}

The government consumes $G_{j t} \geq 0$ amount of good produced by sector $j=1, \ldots, N$ in period $t$. The government consumption is treated as exogenous. The government collects taxes on output, labor and capital incomes. We abstract from the government borrowing for simplicity and impose a balanced budget in every period. The government budget constraint can be written as

$$
T_{t}=\sum_{j=1}^{N} \tau_{j} p_{j t} Y_{j t}+\tau_{h} W_{t} H_{t}+\tau_{k} R_{t} K_{t}-\sum_{j=1}^{N} p_{j t} G_{j t}
$$


The transfer $T_{t}$ acts as an absorber. The budget surplus is rebated back to the households, while the budget deficit is covered by extra taxes.

\subsection{Competitive equilibrium}

A perfectly competitive equilibrium consists of sector-specific quantities $\left\{c_{j t}, x_{j t}, h_{j t}, Y_{j t}\right.$, $\left.K_{j t}, L_{j t}, M_{j t}, K L E_{j t}, E_{j t}, F S_{j t}\right\}_{t=0}^{\infty}, M_{j t}=\left\{M_{j t}^{1}, \ldots, M_{j t}^{N}\right\}$ and prices $\left\{w_{j t}, p_{j t}, P_{j t}^{y}\right\}_{t=0}^{\infty}, j=$ $1, . ., N$, aggregate quantities $\left\{C_{t}, H_{t}, X_{t}, K_{t+1}\right\}_{t=0}^{\infty}$ and prices $\left\{P_{t}, Q_{t}, W_{t}, R_{t}\right\}_{t=0}^{\infty}$, and tax instruments $\left\{T_{t}, \tau_{h}, \tau_{k}\right\}_{t=0}^{\infty}$ such that given the process for the productivity shocks (18), the exogenous government consumption $\left\{G_{1 t}, \ldots, G_{N t}\right\}_{t=0}^{\infty}$ and the initial stock of capital $K_{0}$, the following conditions are satisfied:

1. Firms solve the profit maximization problem, taking prices as given;

2. Households solve the utility maximization problem, taking prices as given;

3. The government balances its budget in every period $t \geq 0$;

4. Capital, labor and goods markets clear in every period $t \geq 0$ :

$$
\begin{aligned}
K_{t} & =\sum_{j=1}^{N} K_{j t}, \\
h_{j t} & =L_{j t}, j=1, \ldots, N, \\
Y_{j t} & =c_{j t}+x_{j t}+G_{j t}+\sum_{i=1}^{N} M_{i t}^{j}, j=1, \ldots, N .
\end{aligned}
$$

In our model, output produced in sector $j$ may be generally used as intermediate inputs in the production of other sectors, including sector $j$. It can also be used for private and public consumption and as investment good. Note that a possibility that some of the demands components for good $j$ may take zero values is not ruled out. 


\subsection{Modelling emissions policy}

Coal, and oil and gas are the only polluting goods in our model. The use of these goods emits the $\mathrm{CO}_{2}$ gas in the atmosphere. Specifically, the use of a unit of coal emits $\epsilon_{\text {coal }}>0$ tons of $\mathrm{CO}_{2}$, and the use of a unit of oil and gas produces $\epsilon_{\text {oil }}>0$ tons of $\mathrm{CO}_{2}$. The emissions factors $\epsilon_{\text {coal }}$ and $\epsilon_{\text {oil }}$ are determined by the existing technology, with $\epsilon_{\text {coal }}>\epsilon_{\text {oil }}$. 3 The level of emissions is defined by the total use of coal, and oil and gas. In equilibrium, the latter is equal to the gross output in each sector. The emissions are then defined by

$$
E M_{t}=\epsilon_{\text {coal }} Y_{\text {coal }, t}+\epsilon_{o i l} Y_{o i l, t}
$$

We consider three types of regimes: a benchmark without emissions controls (No policy), a cap-and-trade emissions policy and a carbon tax. In the absence of emissions regulations, the level of emissions, determined by (16) varies freely.

Emissions cap A cap imposes an upper limit $\overline{E M}_{t}$ on emissions in period $t$ :

$$
E M_{t} \leq \overline{E M}_{t}
$$

The targeted level of emissions is achieved by trading emissions permits. All users of coal, and oil and gas are requested to buy emissions permits at the price $p_{t}^{e m}$, defined per ton of $\mathrm{CO}_{2}$. The price of permits adjusts to clear the permits market. If the emissions cap is not biding, the permit price is zero. The Kuhn-Tucker orthogonality conditions are $p_{t}^{e m} \cdot\left[E M_{t}-\overline{E M_{t}}\right]=0$ and $p_{t}^{e m} \geqslant 0$. The emissions policy directly increases the user price of fossil fuels, which becomes

$$
p_{j t}=P_{j t}^{y} /\left(1-\tau_{j}\right)+p_{t}^{e m} \epsilon_{j}, j \in\{\text { coal, oil }\} .
$$

\footnotetext{
${ }^{3}$ We abstract from modelling abatement technologies in this study in order to focus on the implications of energy input substitutability in evaluating the cap and tax policy instruments.
} 
Emissions tax With a tax policy, the government imposes an exogenous $\operatorname{tax} \tau_{t}^{e m}$ on the use of fossil fuels proportional to their emission content. The tax is defined per ton of $\mathrm{CO}_{2}$. In contrast to the cap regime, the price of emissions becomes fixed to the level determined by the government, $p_{t}^{e m}=\tau_{t}^{e m}$. The emissions $E M_{t}$ adjust endogenously.

The sale of the permits and the carbon tax generate extra revenues for the government in the amount $p_{t}^{e m} E M_{t}$. These revenues are rebated to representative households.

\section{Model parameterization and solution}

The model is calibrated to the U.S. economy. The period of the model is one year. This section outlines the data sources, the aggregation procedure to construct empirical analogues of the theoretical sectors, the parameter calibration, the solution method and simulations. Further details are provided in the Technical Appendix.

\subsection{Sectoral data and aggregation}

The industry-level information on the input-output structure and the decomposition of the demand components is based on the National Income and Product Accounts, the U.S. annual and the 2002 benchmark Input-Output (I-O) accounts published by the Bureau of Economic Analysis (BEA), and the data set of Jorgenson (2007). The Jorgenson's data set provides annual series on the industry-level prices and quantities for gross output and use of primary and intermediate inputs in the U.S. economy. The data sets covers 35 industries for the period from 1960 to $2005 .^{4}$

All industry data from the Jorgenson's data set and the I-O accounts are aggregated into empirical analogues of the six theoretical sectors. Table 1 presents our industry classification for both data sources. Jointly, the industries that comprise the COAL, OIL and ELEC sectors are the same industries that define the energy input in the Jorgenson's data set.

\footnotetext{
${ }^{4}$ The Jorgenson's data set is typically used for multi-sector business cycle models (Horvath, 2000; Kim and Kim, 2006; Bouakez at el., 2009). The data set is available at http://scholar.harvard.edu/jorgenson/data.
} 
Several adjustments are applied to the BEA data to obtain comparable energy sectors, as the Technical Appendix explains. Our characterization of an industry as services follows the BEA characterization. The division of the remaining industries between energy-intensitve and non-energy intensive is based on the definition of the energy intensive industries by the U.S. Department of Energy. ${ }^{5}$

The industry-level data of the U.S. economy are aggregated following the procedure from Jorgenson et al. (1987). ${ }^{6}$ Sectoral and aggregate inputs and gross output in nominal terms simply equal to the sum of the nominal values of their components. Real quantities are the Törnqvist chain indices. The prices are equated with the implicit price deflators. In addition to gross output, two other concepts of output are used in this study: the KLE aggregate and value added. The KLE aggregate helps to understand the role of energy in business cycles. Equation (2) defines the KLE aggregate in the model. This aggregate is constructed as the Törnqvist index for the U.S. data. Value added is typically used in business cycle research. Both in the model and in the data, sectoral and aggregate values added are constructed as in Horvath (2000).

The sectoral data are combined to construct an input-output table of the U.S. economy that corresponds to the six theoretical sectors of the model. Our calculations are based on three types of historical shares. The average shares of input factor costs in total costs are based on the Jorgenson's data set. The average use of the sectoral output for private and public consumption, and investment is inferred from the annual BEA I-O accounts. To be consistent with the closed economy framework, empirical GDP is defined as the domestic component of output. This assumption is not very restrictive for the U.S. economy, in which net exports are historically a relatively small fraction of total GDP. The average producer taxes are based on the value of indirect taxes in GDP in the annual BEA I-O accounts.

The historical shares are used to decompose a fictional GDP of the $\$ 1,000$ value. The

\footnotetext{
${ }^{5}$ http://www1.eere.energy.gov/manufacturing/rd/industries.html

${ }^{6}$ The same procedure is used by the Bureau of Labor Statistics.
} 
I-O table based solely on the historical shares does not provide a balanced account, in which the use of output is equal to total factor payments for every sector. The corrections are made with the RAS method. This method is commonly used in the computable general equilibrium literature. The method essentially redistributes the use of intermediate inputs keeping other entries of the I-O table untouched. ${ }^{7}$ Table 2 provides a balanced historical input-output breakdown of the U.S. economy for the six sectors of the model. This table is used to calibrate the steady state of the model as well as the parameters of various aggregates.

The rows of Table 2 describe how sectoral output is used by other sectors as an intermediate input and how it is used for consumption and investment. For example, coal is used as an intermediate input only, and none of coal is used by services. The columns break down total costs of each sector into input costs and producer taxes. For example, labor is the most costly input for the COAL sector, and the largest expenditures on material inputs are attributed to the COAL sector itself.

\subsection{Parameter choice}

The user prices, the sectoral wage and the values of all price indices are normalized to one in the steady state. This is achieved by the choice of the scale factors $\bar{A}_{j}, A_{j}^{E}, A_{j}^{F}, A_{c}$, $A_{h}$ and $A_{x}$. The price normalization implies that Table 2 provides the steady state values of various quantities in the model with no emissions policy.

Production parameters The elasticities of substitution between coal and oil, and between the fossil fuels and electricity are equalized across the sectors. The values $\sigma_{F j}=0.5$ and $\sigma_{E j}=0.95$ are based on Beckman and Hertel (2009). Note the production complementarities between the energy inputs. The implied parameters $a_{F j}$ and $a_{E j}$ are inferred from the cost shares in the total expenditures on the fossil fuels and energy implied by Table 2 . The parameters $\alpha_{K j}$ and $\alpha_{L j}$ are the cost shares of capital and labor in the KLE aggregate

\footnotetext{
${ }^{7}$ See Schneider and Zenios (1990) for an intereting discussion on the rationale behind the bi-proportionate RAS adjustment techniques and their mathematical properties.
} 
implied by Table 2. The parameters of the Leontief function are computed from the ratios of steady state values of the KLE aggregate and non-energy intermediate inputs to gross output. Consistent with the business cycle research, the annual depreciation rate is $\delta=0.10$.

Table 3 reports the selected production parameters. Three features of the data are notable. First, there is a substantial heterogeneity in the production technologies across the sectors. Second, the production of oil and gas is very oil intensive. As a result, the direct effects of the emissions regulation on the user price of oil are expected to be amplified. Third, the ELEC sector is the largest user of coal, and hence is the largest polluter.

Productivity shocks Sectoral productivity shocks are constructed as residuals based on the definition (2) of the KLE aggregate:

$$
\ln Z_{j t}=\ln K L E_{j t}-\alpha_{K j} \ln K_{j t}-\alpha_{L j} \ln L_{j t}-\left(1-\alpha_{K j}-\alpha_{L j}\right) \ln E_{j t},
$$

Here $\ln K L E_{j t}, \ln K_{j t}, \ln L_{j t}$ and $\ln E_{j t}$ are the HP-filtered cyclical components of the empirical quantity series and the parameters $\alpha_{K j}$ and $\alpha_{L j}$ are the average cost shares implied by the Jorgenson's data set. The persistence coefficients $\rho_{j}$ are the OLS estimates of the individual regressions (18). The covariance matrix $\Omega$ is computed based on the estimated residuals. Table 3 reports the resulting parameters. These parameters are used to generate productivity shocks in the numerical simulations.

Preference parameters The weights in the consumption and investment composites $\xi_{j}$ and $\gamma_{j}$ equal to the shares of sector $j$ in the aggregate consumption and investment expenditures in Table 2. Based on the sectoral input data, Horvath (2000) estimates the elasticity of substitution between sectoral hours of 0.996 , with a standard deviation of 0.0027 . The value $\zeta=1$ is consistent with this estimate. The weights $\eta_{j}$ are the shares of labor input in sector $j$ in total hours worked. The steady state value of hours $H^{*}=0.20$ is from King and Rebelo (1999). Twenty percent of the available time in the steady state of the model with no emissions policy is devoted to work. The value of hours is achieved by the choice of 
the disutility of leisure $\chi$. The discount factor $\beta=0.937$ implies the annual after tax rate of capital return of $6.72 \%$, based on the profits information in Table 2 .

Policy parameters The labor and capital income taxes $\tau_{h}=0.32$ and $\tau_{k}=0.35$ are from McGrattan and Prescott (2010). The output taxes are the ratios of the indirect taxes to gross output in Table 2. Government consumption is $G_{j t}=\bar{G}_{j}$, where $\bar{G}_{j}$ coincides with the values Table 2. Government consumption is held constant over time to avoid confounding the effects of the fiscal and emissions policies. If productivity growth were included in the model, this assumption would be equivalent to assuming that public consumption in each sector was growing at the rate of the sectoral TFP growth. The values $G_{j t}=\bar{G}_{j}$ are based on the entries in Table 2.

\subsection{Solution method and simulations}

The model is solved numerically using the extended deterministic path as suggested by Fair and Taylor (1983). Taylor and Uhlig (1990), Gagnon (1990) and Taylor and Uhlig (2008) provide excellent details on the solution strategy. The method has the advantage of being more accurate relative to linearization techniques. Further, it is more suitable than the first order approximation for analyzing the effects of large shocks. ${ }^{8}$

The emissions policy considered here corresponds to the permanent $20 \%$ emissions reduction from the no policy deterministic steady state level. This target is chosen for the consistency with the existing and prospective legislations in the U.S. and Europe, and with the FS (2011) model. The policy is implemented in the initial period of the model. In all experiments, the economy starts at the no policy steady state.

The model is first solved in the absence of productivity shocks. The solution under the cap gives a path of the endogenous permit price that delivers the target emissions in all periods. This permit price is used as the value of the carbon tax. The behavior of all

\footnotetext{
${ }^{8}$ Basically, the model is solved as a two-point boundary problem, in which initial conditions are imposed on the state variables and the terminal (steady state) conditions are imposed on the co-state variables in the final period $\mathrm{T}$.
} 
variables is thus identical under the cap and the tax in the deterministic case.

The results for the stochastic case are based on a series of numerical simulations for no policy, cap and tax regimes. Five combinations of productivity shocks are considered in each policy regime. A baseline specification All includes productivity shocks in all six sectors of the economy. Productivity shocks originating in the energy-producing sectors jointly (Energy) and in the oil and gas sector alone (Oil) capture energy supply shocks. Productivity shocks in the energy-intensive sector (En.Int.) and in the non-energy intensive and service sectors (Other) affect energy demand.

For each regime, we ran 500 replications of the stochastic economy, with a duration of 100 periods. The tax rate was kept at its values in the deterministic case. The model was implemented using GAMS (the General Algebraic Modeling System) software. The Kuhn-Tucker method was used to account for the orthogonality conditions. The solution method was not successful in all replications under the cap. ${ }^{9}$ To ensure the comparability of the results across the scenarios, we used exactly the same replications for which the solution was found for all types of productivity shocks and all policy regimes. The total number of successful replications was 440. In computing business cycle moments, the first 54 simulations periods were truncated in order to eliminate the dependence on the initial conditions in the no policy case and the effects of the transitional dynamics in response to the introduction of emissions controls. The length of 46 years corresponded to the length of the empirical sample in the Jorgenson's data set. Unless specified otherwise, the numerical moments were computed by averaging the statistics across the replications.

\footnotetext{
${ }^{9}$ Under the cap, the solution was found in 457 replications for All, 498 for En.Int. and 484 for Other cases. In all other cases the method was successful for all replications.
} 


\section{Effects of the emissions policy without productivity shocks}

Table 4 gives the responses of aggregate and sectoral variables to the introduction of the emissions regulation on impact and in the long-run. The reported numbers are the percentage changes from the no policy deterministic steady state. Recall that the cap and the tax instruments are equivalent in the absence of productivity shocks by construction.

The emissions regulation reduces the levels of all aggregate quantities both on impact and in the long run (panel A, Table 4). Initially, there is a strong impact on investment as the stock of capital is above the desired level. There is a period of a smooth transition to the new steady state, which take about twenty five years to complete. The new steady state of output in the model with input-output linkages is much smaller than in the FS (2011) model, even though the policy impact on consumption is of a comparable magnitude.

Panels B-D of Table 4 illustrate a heterogeneity of sectoral responses to the emissions policy. The emissions reduction is achieved through the increased user price of the fossil fuels. Since coal is more polluting, coal becomes more expensive input than oil and gas. The increased user cost of the fossil fuels, combined with the change in their relative prices, triggers a series of the cascading input substitution and price effects discussed in section 2.1. In all sectors, the index prices of the fossil fuels and energy rises (panel B), while the demand for the intermediate use of the fossil fuels, electricity and total energy falls (panels A and D). As expected, the magnitude of the responses depends on the energy share in production.

The emissions policy induces a reallocation of labor and capital. Labor flows from the energy producing to other sectors of the economy and towards increasing leisure. The aggregate and sectoral wages decline to accommodate lower labor demand, with an exception of the ELEC sector. While capital is lower in all sectors in the long-run, there is a sectoral shift to the sectors in which the marginal product of capital falls the least on impact. The policy effect on the production side culminates in the reduction of outputs in all sectors.

The effects of the emissions regulation are transmitted through the economic sectors in 
several ways. First, the increase in the price of energy directly increases the production costs in all the sectors. Second, the supply effects of higher production costs are amplified by raising the prices of the intermediate inputs produced in the energy-intensive sectors. Third, higher energy prices also have the demand effect, which arises if the output of a sector is used by an energy-intensive sector. If the supply effects dominate the demand effect in sector $j$, its output should fall, but its price should increase. If the demand effect is stronger, both output and price should fall in responses to the emissions policy. ${ }^{10}$

Panels A and B of Table 4 describe an interesting pattern of output and price responses across the sectors. Gross output and value added decline in all sectors. However, there is a diversity in the responses of producers prices $P_{j t}^{y}$. The producer price increases in the sectors with the largest energy costs shares, OIL, ELEC and EIN. The emissions regulation acts largely as a supply shock in these sectors. By contrast, the regulation mainly reduces the demand for the remaining sectors COAL, NEIN and SERV. Output prices in these sectors decline. The differences between the producer and user prices for COAL are noteworthy. Despite a sharp increase in the user price of coal, its producer price decreases, due to a fall in the demand for this most polluting good.

The pattern of output and price responses is consistent with the findings of Lee and $\mathrm{Ni}$ (2002). These authors derive the impulses responses of selected U.S. industries to oil price shocks using a vector autoregression framework, and supplement the econometric analysis with narrative accounts from industry trade journals. The results indicate that oil price increases mainly reduce supply of oil-intensive industries, such as petroleum refinery and industrial chemical and synthetic materials. By contrast, many other industries experience a reduction in demand. For example, five out of fourteen industries studied by Lee and $\mathrm{Ni}$ (2002) are classified as non-energy intensive in our study. Both output and price fall for the apparel, household furniture, household appliance and automobile industries.

\footnotetext{
10 In equilibrium, the decisions of the firms are consistent with the decisions of the households. We abstract here from discussing the usual general equilrium effects.
} 
Panel D of Table 4 reports the percentage change in the sectoral levels of emissions and the emission intensities. The use of coal is penalized most by the emissions policy. The sectors that are more dependent on coal (COAL, EIN and ELEC) have the largest reduction in the emission intensities.

\section{Results for the stochastic case}

This section first evaluates the ability of the model with stochastic productivity shocks to replicate aggregate and sectoral business cycle statistics in the absence of the emissions regulation. Then it asks how its predictions change under the cap and the tax policies.

\subsection{Business cycle properties: no policy}

Table 5 reports the key business cycle moments of the aggregate variables in the model with all productivity shocks and no emissions policy. It also gives empirical counterparts of the statistics from the U.S. economy. Aggregate value added is the Törnqvist aggregate of sectoral value added. Consumption and investment are real total private consumption and investment expenditures from the BEA. Hours are the Törnqvist aggregate of labor input from the Jorgenson's data set. All U.S. data are logged and detrended with the HP filter with the smoothing parameter set at 100 prior to computing the moments. The simulated data are not filtered.

Our model matches rather well volatilities and correlations of the U.S. economy. First, aggregate value added in the model captures about $80 \%$ of the volatility of the actual output. Second, the model correctly reproduces the properties that consumption is less while investment is more volatile than output. Third, hours are less variable than output, but more variable than consumption. The model falls short of reproducing the exact relative magnitude of the standard deviations of consumption and hours. Excessive smoothness of these variables is a common problem of many business cycle models. Furthermore, as noted 
by Horvath (2000), equating the weights in the consumption aggregator (11) with empirical consumption shares hinders the model's ability to generate consumption volatility relative to the case where all components have equal weights. This is because the least volatile service sector accounts for eighty percent of total consumption expenditures. Finally, all aggregate variables are highly procyclical in the model and in the data. The predicted correlation between total emissions and output is remarkably close to the empirical correlation between the monthly cyclical components of $\mathrm{CO}_{2}$ emissions and GDP computed by Heutel (2012).

For comparison, Table 5 also reports the statistics from Kim and Kim (2006) and FS (2011). Kim and Kim (2006) use a multi-sector model with the same preferences as ours, but different production structure and higher level of industry disaggregation to analyze the role of intermediate inputs and preferences in explaining sectoral comovement and volatility. The results in Table 5 imply that the predictions of our model are similar and on some dimensions superior to those in Kim and Kim (2006) and FS (2011).

Table 6 reports the volatilities of sectoral variables in the model with all productivity shocks and in the U.S. data. The model broadly captures the ranking of standard deviations of value added and labor inputs. Two exceptions are the EIN and NEIN sectors for value added, and the EIN and OIL sectors for labor, where the ranking is reversed. The labor volatility is too low in comparison with the data. This prediction, however, is shared with other multi-sector business cycle models (Kim and Kim, 2006). The model overpredicts the volatility of capital, which may be due to the absence of any frictions in the capital market. The model falls short of capturing the relative volatility of energy inputs. We are not aware of a study that reports comparable statistics for the sectoral energy use in a multi-sector DSGE model. It is also worth pointing out that our closed economy model abstracts from energy price movements in the world markets. The latter will certainly be responsible for part of the variation of energy inputs in the U.S. economy. 


\subsection{Aggregate impact of the emissions policy}

The comparison of the cap and the tax instruments starts by examining their implications for emissions. Panel A of Table 7 reports the average emission reduction relative to the no policy case. The cap imposes an upper constraint on the level of emissions in every period. This constraint was not binding in a limited number of cases. ${ }^{11}$ The tax policy was successful in achieving the twenty percent emission reduction on average.

Panels $\mathrm{B}$ and $\mathrm{C}$ of Table 7 report the average standard deviations of macroeconomic aggregates in the cap and tax regimes. The volatility of all aggregate variables is uniformly lower under the cap relative to the tax policy in all the cases. According to one-sided Kolmogorov-Smirnov tests, the differences are statistically significant for the case of all shocks, and for the productivity shocks originating in the energy sectors. By contrast, the equivalence of the standard deviations for non-energy productivity shocks cannot be rejected.

\subsection{Welfare comparison}

Table 8 turns to the policy welfare costs in the deterministic and stochastic environments. Total welfare costs are defined as the percentage change in annual consumption from the no policy deterministic steady state needed to achieve the same level of utility in the no policy and no uncertainty scenario as the expected level of utility in the stochastic environment with the emissions policy. We follow Otrok (2001) in computing the expected utility by averaging the utilities across the replications. The utility function (10) is separable in consumption and leisure. The statistics in Table 8 correspond to the welfare cost of the consumption component of the utility only. This approach allows us to compare out results with the existing studies. Our model is also likely to overestimate the welfare benefits of higher leisure brought about by the emissions regulations. ${ }^{12}$

The statistics in panels A and B of Table 8 include the transition periods in the welfare

\footnotetext{
${ }^{11}$ The emissions were below the target in 15, 11 and 9 periods in the All, Energy and Oil simulations.

${ }^{12}$ The welfare ranking of the cap and tax policies still holds when changes in leisure are taken into account.
} 
calculations. The 30-year horizon is chosen for comparability with the values in FS (2011). The 100 years is the number of the simulation periods in each replication. Panel $\mathrm{C}$ provides the welfare costs of fluctuations in the economies that completed the transitional adjustment to the emissions regulation. The statistical significance of the differences in welfare costs between the policies is assessed with the Kolmogorov-Smirnov tests applied to the utility levels across the replications.

In the deterministic case, the cap and tax policies are equivalent by construction. Our cost of $0.87 \%$ is comparable with the steady state welfare cost of $0.82 \%$, for both the cap and the tax, in FS (2011). The costs in panel C are larger relative to panel B because the average level of consumption is lower when the transition period is not taken into account.

Two results for the welfare costs in the stochastic environment stand out. First, the origin of the productivity shocks matters. The cap and the tax policies are statistically equivalent from the welfare perspective when productivity shocks come from the non-energy sectors. By contrast, the welfare costs differ for the energy-related productivity shocks. Second, the cap policy is more costly than the tax for the shocks from the energy sectors. The costs under the cap are also higher for all shocks, albeit the difference between the policy regimes is not statistically significant. Interestingly, FS (2011) find that the cap and the tax policies are equivalent in the long run., but that the cap is more costly when the transition periods are included in the welfare calculations.

The welfare ranking of the cap and the tax instruments can be considered puzzling. The risk-averse households dislike consumption fluctuations. Why wouldn't the cap regime, delivering lower consumption volatility, be preferred to the tax? FS (2011) explain the cap dominance by the transition periods. This is not the case in our model. Our modelling strategy ensures that the deterministic path of consumption in the transition periods is the same under the cap and the tax. The superiority of the tax policy over the cap policy for the simulations with the productivity shocks in the energy sectors persists even in the long 
run. The reason is that not only the standard deviations but also other characteristics of consumption distribution depend on the policy regime.

Figure 1 plots kernel densities of consumption. To get meaningful estimates, consumption realizations in the same period across the 440 replications are treated as a separate random sample. The curves in Figure 1 are the averages of the probability densities over the 46 simulation periods. While there are minimal differences in the densities under the cap and the tax policies in panels $\mathrm{D}$ and $\mathrm{E}$, the densities are quite distinct in panels $\mathrm{B}$ and $\mathrm{C}$.

Table 9 complements Figure 1. Panel A reports the results of the Kolmogorov-Smirnov tests of the distribution equivalence of consumption under the cap and the tax policies, by simulation periods. Consistent with the welfare results, the equivalence of consumption distributions can be rejected only for the case of productivity shocks from the energy sectors. Panels B and C of Table 9 give additional statistics. The cap reduces not only the volatility of consumption, but also its mean and median values, relative to the tax. Consumption distribution becomes skewed to the left under the cap, on average. These distributional differences are reflected in the welfare costs measures. ${ }^{13}$

The emissions constraint under the cap effectively restricts the joint production of the COAL and OIL sectors. The tax introduces a fixed component to the user prices of the fossil fuels, but allows emissions and hence the joint production of the fossil fuels to adjust. The responses to positive and negative shocks under the tax are symmetric. It appears that the cap restricts the ability of the economy to respond to positive productivity shocks by more than it does for the negative productivity shocks. The advantage of our solution method is worth highlighting. The asymmetries in the responses cannot be detected with the use of the first order linearization techniques.

\footnotetext{
${ }^{13}$ We focus on consumption since it is central for welfare comparison. However, the distributions of other economic variables are affected in a similar way.
} 


\subsection{Sectoral impact of the emissions policy}

The analysis of the aggregate variables hides important variations in sectoral responses. The differences under the cap and the tax policies are the strongest for gross output. Table 10 reports standard deviations of gross output by types of the simulations. Several findings emerge from this table.

First, volatility of all sectors is different between the cap and the tax policies for the simulations with the productivity shocks originated in the energy sectors. The differences are statistically significant, according to the Kolmogorov-Smirnov tests. Interestingly, the effects of the emissions policy on sectoral volatility are not washed out when all productivity shocks are considered jointly. Second, relative to the tax policy, the cap reduces output volatility in all sectors, except COAL. Production of coal is more variable under the cap, apart for the simulations with productivity shocks in the NEIN and SERV sectors. The cap imposes tighter restrictions on the economy to adjust to energy supply shocks. Since coal is the most polluting good, the demand for this product adjusts by more when the constraint on the joint production of the fossil fuels is in place. Third, productivity shocks from the non-energy sectors have distinct sectoral impacts under the cap and the tax policies, even though there are no significant differences on the aggregate variables. While the impacts are the strongest on the COAL and OIL sectors, the volatility of the ELEC and the EIN sectors is also affected.

Finally, volatility is not the only distinctive feature of gross output in the COAL and OIL sectors under the cap and the tax policies. Table 11 provides two additional statistics. The cap makes the production in these two sectors be almost perfectly negatively correlated, due to the emissions constraint. This negative correlation is in sharp contrast with the positive correlation between sectoral outputs in the U.S. data, and with the results in no policy scenario. The cap also introduces significant asymmetries in output responses. The distribution of output becomes skewed to the right for the COAL sector and to the left for 
the OIL sector. Figure 2 provides a graphical illustration of the distribution, by plotting the average kernel densities.

\section{Conclusions}

This study evaluates cap-and-trade and carbon tax policies for controlling emissions from a business cycle perspective. In contrast to previous research, the analysis is based on a DSGE model with multiple sectors and sectoral productivity shocks. The results provide new insights on the choice between the cap and the tax instruments.

First, the origin of productivity shocks matters. The model predicts significant differences in welfare and volatility of aggregate and sectoral variables under the cap and the tax policies when shocks to the energy production are taken into account. Relative to the tax, the cap policy reduces the volatility of all aggregates. However, the cap is not the best policy from the welfare perspective. This policy can introduce important asymmetries in responses of the economy to positive and negative shocks to production of coal, and oil and gas. These energy producing sectors are directly affected by emissions regulation.

Second, the cap and the tax policies have distinct sectoral impacts, which are the most pronounced in the fossil fuels sectors. COAL is the only sector with larger volatility under the cap. The cap policy also affects the skewness of output distributions in the COAL and OIL sectors. The sectoral differences are present even in the simulations with productivity shocks that have no significant impact on macroeconomic aggregates.

There are several possible extensions of our work. An open question is whether the policy ranking with respect to economic volatility and welfare remains the same in an open economy. The terms of trade shocks, which cannot be examined in the current specification, is particularly interesting. The fiscal policy is held fixed in the model, and the government revenues, generated by the emissions policy, are rebated to the households in a lump-sum

way. A joint determination of optimal fiscal and emissions polices that account for the 
effects of distortionary taxes would be a useful exercise. Finally, we model the real side of the economy. A model with nominal rigidities would answer how the emissions regulations would alter the economy's responses to monetary policy shocks.

\section{References}

Beckman, J., Hertel, T., 2009. Why previous estimates of the cost of climate mitigation are likely too low. GTAP Working Papers 2954, Center for Global Trade Analysis, Department of Agricultural Economics, Purdue University.

Bouakez, H., Cardia, E., Ruge-Murcia, F. J., 2009. The transmission of monetary policy in a multisector economy. International Economic Review 50 (4), 1243-1266.

Fair, R. C., Taylor, J. B., 1983. Solution and maximum likelihood estimation of dynamic nonlinear rational expectations. Econometrica 51, pp. 1169-1185.

Fischer, C., Springborn, M., 2011. Emissions targets and the real business cycle: Intensity targets versus caps or taxes. Journal of Environmental Economics and Management 62 (3), $352-366$.

Gagnon, J. E., 1990. Solving the stochastic growth model by deterministic extended path. Macroeconomic Dynamics 8 (1), pp. 35-36.

Heutel, G., 2012. How should environmental policy respond to business cycles? Optimal policy under persistent productivity shocks. Review of Economic Dynamics 15 (2), 244264.

Horvath, M., 2000. Sectoral shocks and aggregate fluctuations. Journal of Monetary Economics 45 (1), 69-106.

Jorgenson, D. W., 2007. 35 sector KLEM. Sectoral input-output database, IQSS Dataverse Network.

URL http://hdl . handle.net/1902.1/10684

Jorgenson, D. W., Gollop, F. M., Fraumeni, B. M., 1987. Productivity and U.S. economic growth. Harvard Economic Studies, vol. 159 Cambridge, Mass.: Harvard University Press.

Kim, K., Kim, Y. S., 2006. How important is the intermediate input channel in explaining sectoral employment comovement over the business cycle? Review of Economic Dynamics $9(4), 659-682$.

King, R. G., Rebelo, S. T., 1999. Resuscitating Real Business Cycles. In: Taylor, J. B., Woodford, M. (Eds.), Handbook of Macroeconomics. Vol. 1B of Handbooks in Economics, vol. 15. Elsevier, Amsterdam, pp. 927-1007. 
Lee, K., Ni, S., 2002. On the dynamic effects of oil price shocks: a study using industry level data. Journal of Monetary Economics 49 (4), 823-852.

McGrattan, E. R., Prescott, E. C., 2010. Unmeasured investment and the puzzling US boom in the 1990s. American Economic Journal: Macroeconomics 2 (4), 88-123.

Metcalf, G., 2009. Market-based policy options to control U.S. greenhouse gas emissions. Journal of Economic Perspectives 23 (2), 5-27.

Otrok, C., 2001. On measuring the welfare cost of business cycles. Journal of Monetary Economics 47 (1), $61-92$.

Schneider, M., Zenios, S., 1990. A comparative study of algorithms for matrix balancing. Operations Research 38 (3), 439 - 55.

Taylor, J. B., Uhlig, H., 1990. Solving nonlinear stochastic growth models: A comparison of alternative solution methods. Journal of Business \& Economic Statistics 8 (1), 1-17.

Taylor, J. B., Uhlig, H., 2008. Computation of business cycle models: A comparison of numerical methods. Journal of Business and Economic Statistics 12, pp. 641-663.

Weitzman, M., 1974. Prices versus quantities. The Review of Economic Studies 41 (4), 477491. 
Table 1: Classification of the U.S. industries into the sectors of the model Industry from the Jorgenson's Industry from the BEA tables data set (industry number) (NAICS industry code)

A. COAL: Coal sector in the model

Coal mining (3) Coal mining (212100) part of Mining,

except oil and gas (212)

B. OIL: Oil and gas sector in the model

Crude oil and gas extraction (4) Oil and gas extraction (211)

Petroleum refining (16) Petroleum and coal products (324)

Gas utilities (31)

Natural gas distribution (221200) part of Utilities (22)

C. ELEC: Electricity sector in the model

Electric utilities (30) Electric power generation, transmission,

and distribution (221100) part of Utilities (22)

D. EIN: Energy intensive producers

\begin{tabular}{ll}
\hline Metal mining (2) & Mining, except oil and gas (212) \\
Non-metallic mineral mining (5) & less Coal mining (212100) \\
Lumber and wood products (11) & Wood products (321) \\
Paper and allied products (13) & Paper products $(322)$ \\
Chemicals and allied products (15) & Chemical products (325) \\
Rubber and plastic products (17) & Plastics and rubber products (326) \\
Stone, clay and glass products (19) & Nonmetallic mineral products (327) \\
Primary metals (20) & Primary metals (331)
\end{tabular}

Primary metals $(20)$

E. NEIN: Non-energy intensive producers

\begin{tabular}{ll}
\hline Agriculture, forestry, fisheries (1) & Farms (111CA) \\
Food and kindred products (7) & Forestry, fishing, and related activities (113FF) \\
Tobacco manufactures (8) & Food and beverage and tobacco products (311FT) \\
Textile mill products (9) & Textile mills and textile product mills (313TT) \\
Apparel and other textile products (10) & Apparel and leather and allied products (321) \\
Furniture and fixtures (12) & Furniture and related products (337) \\
Printing and publishing (14) & Printing and related support activities (323) \\
Leather and leather products (18) & Fabricated metal products (332) \\
Fabricated metal products (21) & Computer and electronic products (334) \\
Non-electrical machinery (22) & Machinery (333) \\
Electrical machinery (23) & Motor vehicles, bodies and trailers, and parts (3361MV) \\
Motor vehicles (24) & Other transportation equipment (3364OT) \\
Other transportation equipment (25) & Electrical equipment, appliances, and components (335) \\
Instruments (26) & Miscellaneous manufacturing (339) \\
Miscellaneous manufacturing (27) & \\
\hline & \\
F. SERV: Services & Construction (23) \\
Construction (6) & Wholesale trade (42) Retail trade (44RT) \\
Wholesale and retail trade (32) & Transportation and warehousing (48TW) \\
Transportation and warehousing (28) & Information (51) \\
Communications (29) & Finance, insurance, real estate, rental, and leasing (FIRE) \\
Finance, insurance and real estate (33) & Professional and business services (PROF) \\
Personal and business services (34) & Educational services, health care, and social assistance (6) \\
Government enterprises (35) & Government (G)Support activities for mining (213) \\
& Water, sewage and other systems (221300) \\
& part of Utilities (22) \\
\hline \hline
\end{tabular}


Table 2: Input-output table, based on historical U.S. averages and a GDP value of $\$ 1,000$

\begin{tabular}{l|rrrrrr|rrr}
\hline \hline & COAL & OIL & ELEC & EIN & NEIN & SERV & C & I & G \\
\hline COAL & 0.73 & 0.01 & 4.47 & 1.25 & 0.13 & 0.00 & 0.00 & 0.00 & 0.00 \\
OIL & 0.11 & 43.00 & 4.50 & 5.14 & 3.10 & 15.68 & 15.48 & 0.27 & 0.00 \\
ELEC & 0.11 & 1.26 & 0.63 & 6.62 & 5.17 & 18.21 & 11.84 & 0.00 & 0.00 \\
EIN & 0.20 & 6.23 & 1.35 & 60.16 & 47.25 & 52.56 & 19.55 & 0.45 & 0.00 \\
NEIN & 0.53 & 1.42 & 1.37 & 15.40 & 192.80 & 107.00 & 104.27 & 61.02 & 9.78 \\
SERV & 0.37 & 4.71 & 3.48 & 23.47 & 44.76 & 209.82 & 624.26 & 126.01 & 27.06 \\
\hline Wages & 2.19 & 8.08 & 7.37 & 46.40 & 137.61 & 410.62 & & & \\
Indirect taxes & 0.82 & 3.67 & 5.19 & 2.39 & 4.75 & 57.27 & & & \\
Profits & 1.52 & 18.87 & 15.50 & 26.93 & 58.03 & 192.78 & & & \\
\hline \hline
\end{tabular}

Notes: This table reports a decomposition of a fictional GDP value of $\$ 1,000$ into factor costs and expenditure categories. The decomposition is computed by the authors based on the historical cost shares from Jorgenson's data set and the Input-Output accounts from the BEA. Entries may not add up due to rounding. 
Table 3: Selected production-related parameters

\begin{tabular}{rrrrrrr}
\hline \hline \multicolumn{7}{c}{ A. Shares and productivity shock persistence } \\
\hline COAL & OIL & ELEC & EIN & NEIN & SERV \\
Capital share in KLE, $\alpha_{K j}$ & 0.325 & 0.265 & 0.478 & 0.312 & 0.284 & 0.302 \\
Labor share in KLE, $\alpha_{L j}$ & 0.470 & 0.113 & 0.227 & 0.537 & 0.674 & 0.644 \\
Energy share in KLE, 1- $\alpha_{K j} \alpha_{L j}$ & 0.205 & 0.622 & 0.296 & 0.151 & 0.041 & 0.053 \\
Implied share of $M_{j}^{\text {coal }}$ in $F S_{j}$ & 0.870 & 0.000 & 0.498 & 0.196 & 0.040 & 0.000 \\
Implied share of $F S_{j}$ in $E_{j}$ & 0.882 & 0.971 & 0.934 & 0.491 & 0.384 & 0.463 \\
Productivity persistence $\rho_{j}$ & 0.549 & 0.658 & 0.652 & 0.488 & 0.490 & 0.636 \\
\hline B. Variance-covariance matrix, & $100 \times \sqrt{\Omega}$ & & \\
\hline COAL & COAL & OIL & ELEC & EIN & NEIN & SERV \\
OIL & -0.555 & -0.226 & 0.107 & 0.386 & 0.235 & -0.054 \\
ELEC & 0.107 & 0.248 & 1.527 & 0.176 & 0.072 & 0.011 \\
EIN & 0.386 & 0.040 & 0.176 & 3.166 & 0.276 & 0.076 \\
NEIN & 0.235 & 0.423 & 0.072 & 0.276 & 1.841 & 0.129 \\
SERV & -0.054 & -0.025 & 0.011 & 0.076 & 0.129 & 0.912 \\
\hline \hline
\end{tabular}

Notes: The parameters of the productivity shocks are estimated based on the equation (3) and sectoral U.S. data, 1960-2005. Other parameters are implied by Table 2. 
Table 4: Effects of the twenty percent emissions reduction in the deterministic case

\begin{tabular}{|c|c|c|c|c|c|c|c|c|c|c|}
\hline & & & & $\overline{~ A . ~}$ & $\overline{a t}$ & $\overline{\text { ities }}$ & & & & \\
\hline & & $\operatorname{Im}$ & act eff & cts & & & Lon & -run ef & ects & \\
\hline & $\mathrm{Y}$ & $\mathrm{C}$ & $\mathrm{I}$ & $\mathrm{H}$ & $\mathrm{K}$ & $\mathrm{Y}$ & $\mathrm{C}$ & $\mathrm{I}$ & $\mathrm{H}$ & $\bar{K}$ \\
\hline Model & -0.89 & -0.16 & -4.12 & -1.07 & "0 & -1.18 & $\begin{array}{c}-1.08 \\
\end{array}$ & $\begin{array}{l}-1.89 \\
\end{array}$ & -0.55 & $\overline{-1.89}$ \\
\hline $\mathrm{FS}(2011)$ & n.a. & n.a. & n.a. & n.a. & n.a. & -3.30 & -1.10 & & -0.43 & -3.30 \\
\hline & & & & B. Sec & oral ou & $\overline{\mathrm{s} \text { and }}$ & inputs & & & \\
\hline & & $\operatorname{Im}$ & act eff & cts & & & Lon & -run ef & ects & \\
\hline & $\mathrm{Y}(\mathrm{j})$ & $\mathrm{VA}(\mathrm{j})$ & $\mathrm{L}(\mathrm{j})$ & $\mathrm{K}(\mathrm{j})$ & $E(j)$ & $\mathrm{Y}(\mathrm{j})$ & $\mathrm{VA}(\mathrm{j})$ & $\mathrm{L}(\mathrm{j})$ & $\mathrm{K}(\mathrm{j})$ & $E(j)$ \\
\hline COAL & -27.8 & -22.8 & -16.3 & -28.6 & -47.6 & -27.3 & -22.4 & -15.3 & -29.2 & -46.7 \\
\hline OIL & -16.1 & -9.1 & -6.0 & -9.6 & -20.4 & -16.3 & -9.7 & -5.3 & -10.9 & -20.3 \\
\hline ELEC & -5.9 & -0.1 & -0.6 & 1.5 & -20.2 & -6.7 & -1.2 & -0.1 & -0.6 & -20.1 \\
\hline EIN & -1.8 & -0.3 & -0.8 & 1.0 & -10.5 & -2.1 & -0.6 & -0.2 & -0.8 & -10.8 \\
\hline NEIN & -1.2 & -0.9 & -1.3 & 0.1 & -9.0 & -1.3 & -0.9 & -0.6 & -1.6 & -9.2 \\
\hline SERV & -0.8 & -0.3 & -0.9 & 0.9 & -8.3 & -1.1 & -0.7 & -0.4 & -1.1 & -8.9 \\
\hline & & & & & Sect & prices & & & & \\
\hline & & $\mathrm{Im}$ & act eff & cts & & & Lon & -run ef & ets & \\
\hline & $\mathrm{p}(\mathrm{j})$ & $\mathrm{P}^{f s}(\mathrm{j})$ & $\mathrm{P}^{e}(\mathrm{j})$ & $\mathrm{w}(\mathrm{j})$ & $\mathrm{P}^{y}(\mathrm{j})$ & $p(j)$ & $\mathrm{P}^{f s}(\mathrm{j})$ & $\mathrm{P}^{e}(\mathrm{j})$ & $w(j)$ & $\mathrm{P}^{y}(\mathrm{j})$ \\
\hline COAL & 42.0 & 37.8 & 33.5 & -16.5 & -2.6 & 40.3 & 36.4 & 32.3 & -16.6 & -2.3 \\
\hline OIL & 12.5 & 12.5 & 12.3 & -5.7 & 4.8 & 12.6 & 12.6 & 12.4 & -6.2 & 5.2 \\
\hline ELEC & 4.8 & 26.2 & 24.7 & 0.1 & 4.8 & 5.2 & 25.5 & 24.1 & -0.8 & 5.2 \\
\hline EIN & 0.5 & 17.2 & 10.7 & -0.1 & 0.5 & 0.6 & 17.0 & 10.8 & -0.9 & 0.6 \\
\hline NEIN & -0.4 & 12.6 & 7.7 & -0.6 & -0.4 & -0.4 & 12.7 & 8.0 & -1.3 & -0.4 \\
\hline SERV & -0.3 & 12.5 & 7.8 & -0.2 & -0.3 & -0.3 & 12.6 & 8.1 & -1.1 & -0.3 \\
\hline & & & & Energy & anc & $\overline{\text { Ssior }}$ & y sect & & & \\
\hline & & $\operatorname{Im}$ & act eff & $\mathrm{cts}$ & & & Lon & -run ef & cts & \\
\hline & $\mathrm{M}_{j}^{\text {coal }}$ & $\mathrm{M}^{\text {oil }}$ & $\mathrm{M}^{\text {elec }}$ & em.in. & EM & $\mathrm{M}^{\text {coal }}$ & $\mathrm{M}^{\text {oil }}$ & $\mathrm{M}^{\text {elec }}$ & em.in. & $\mathrm{EM}$ \\
\hline COAL & -49.9 & -43.5 & -34.1 & -30.4 & -49.8 & -48.9 & -42.7 & -33.7 & -29.5 & -48.8 \\
\hline OIL & -29.6 & -20.5 & -15.7 & -5.3 & -20.5 & -29.0 & -20.4 & -15.8 & -5.0 & -20.4 \\
\hline ELEC & -25.7 & -16.1 & -5.9 & -19.6 & -24.4 & -25.3 & -16.2 & -6.6 & -18.6 & -24.1 \\
\hline EIN & -23.0 & -12.1 & -5.7 & -17.8 & -19.2 & -22.6 & -12.2 & -6.3 & -17.3 & -19.0 \\
\hline NEIN & -22.3 & -12.3 & -6.5 & -12.4 & -14.4 & -21.8 & -12.3 & -6.9 & -12.3 & -14.4 \\
\hline SERV & 0.0 & -12.1 & -5.8 & -10.4 & -12.1 & 0.0 & -12.6 & -6.5 & -10.6 & -12.6 \\
\hline
\end{tabular}

Notes: The entries report percentage reductions relative to the no policy deterministic steady state. Impact effects are the responses in the period of the introduction of the emissions regulation. Longrun effects correspond to the changes in the steady state values. The FS (2011) statistics are from Fischer and Springborn (2011), Table 4. The columns em.in. indicate emission intensities. 
Table 5: Aggregate volatilities and correlations: the case of 'No policy'

\begin{tabular}{|c|c|c|c|c|}
\hline & "U.S. data & All shocks & "Kim and Kim (2006) & 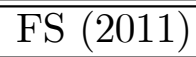 \\
\hline \multicolumn{5}{|c|}{ A. Standard deviation } \\
\hline Output & 2.51 & 2.02 & 1.53 & 3.32 \\
\hline Consumption & 0.68 & 0.48 & 0.45 & 0.75 \\
\hline Investment & 3.13 & 4.14 & 1.98 & n.a. \\
\hline Hours & 0.99 & 0.60 & 0.58 & 0.08 \\
\hline Capital & 0.61 & 0.81 & n.a. & 0.93 \\
\hline \multicolumn{5}{|c|}{ B. Correlation with aggregate value added } \\
\hline Consumption & 0.82 & 0.70 & 0.89 & n.a. \\
\hline Investment & 0.79 & 0.94 & 0.81 & n.a. \\
\hline Hours & 0.85 & 0.90 & 0.93 & n.a. \\
\hline Capital & 0.41 & 0.66 & n.a. & n.a. \\
\hline Emissions & $0.56^{a}$ & 0.53 & n.a. & n.a. \\
\hline
\end{tabular}

Notes: Standard deviations of variables other than output are reported relative to the standard deviation of output. Output is aggregate value added constructed from sectoral value added. U.S. data are logged and detrended with the HP filter with the smoothing parameter of 100. Statistics for column 3 are the averages over 440 replications of the length of 46 periods. The statistics in colum 4 are from Kim and Kim (2006), Table 1, column 5 for band-pass filtered simulation data. The statistics in column 5 are based on Fischer and Springborn (2011), Table 6. The statistics for the emissions ${ }^{a}$ is from Heutel (2011). The abbreviarion n.a. means not available. 
Table 6: Sectoral volatilities: the case of 'No policy'

\begin{tabular}{lcccccccc}
\hline \hline & \multicolumn{4}{c}{ U.S. data } & \multicolumn{4}{c}{ Model with all shocks } \\
& $\mathrm{VA}(\mathrm{j})$ & $\mathrm{L}(\mathrm{j})$ & $\mathrm{K}(\mathrm{j})$ & $\mathrm{E}(\mathrm{j})$ & $\mathrm{VA}(\mathrm{j})$ & $\mathrm{L}(\mathrm{j})$ & $\mathrm{K}(\mathrm{j})$ & $\mathrm{E}(\mathrm{j})$ \\
\hline COAL & 2.22 & 3.19 & 1.74 & 3.29 & 2.51 & 1.41 & 2.63 & 2.20 \\
OIL & 4.83 & 3.10 & 1.66 & 3.22 & 5.16 & 0.88 & 1.90 & 2.88 \\
ELEC & 1.00 & 1.75 & 0.81 & 1.72 & 1.20 & 0.52 & 0.85 & 2.53 \\
EIN & 1.93 & 1.90 & 0.88 & 1.94 & 1.24 & 1.04 & 2.13 & 2.93 \\
NEIN & 1.67 & 1.85 & 0.89 & 1.57 & 1.42 & 0.77 & 1.13 & 2.60 \\
SERV & 0.75 & 0.81 & 0.70 & 1.57 & 0.88 & 0.62 & 0.86 & 2.85 \\
\hline \hline
\end{tabular}

Notes: Standard deviations are reported relative to the standard deviation of aggregate value added. Statistics are the averages over 440 replications of the length of 46 periods. 
Table 7: Impact of the emission policy on aggregate variables

\begin{tabular}{|c|c|c|c|c|c|c|}
\hline & \multicolumn{5}{|c|}{ Simulations by types of shocks } & FS (2011) \\
\hline & All & Energy & Oil & En.Int. & Other & Model \\
\hline \multicolumn{7}{|c|}{ A. Emission reduction relative to No Policy } \\
\hline Cap & -20.00 & -20.00 & -20.00 & -20.00 & -20.00 & -20.00 \\
\hline \multirow[t]{2}{*}{ Tax, mean } & -20.00 & -19.99 & -19.97 & -20.04 & -20.06 & -20.00 \\
\hline & {$[1.49]$} & {$[1.35]$} & {$[1.35]$} & {$[0.06]$} & {$[0.33]$} & n.a. \\
\hline \multicolumn{7}{|c|}{ B. Standard deviation: Cap } \\
\hline Output & 1.91 & 0.40 & 0.37 & 0.54 & 1.60 & 2.94 \\
\hline Consumption & 0.87 & 0.19 & 0.17 & 0.23 & 0.77 & 2.43 \\
\hline Investment & 7.98 & 1.53 & 1.43 & 2.14 & 6.74 & \\
\hline Hours & 1.13 & 0.19 & 0.18 & 0.34 & 0.95 & 0.22 \\
\hline Capital & 1.55 & 0.31 & 0.30 & 0.38 & 1.34 & 2.86 \\
\hline \multicolumn{7}{|c|}{ C. Standard deviation: Tax } \\
\hline Output & 1.98 & 0.51 & 0.49 & 0.55 & 1.62 & 3.40 \\
\hline Consumption & 0.96 & 0.34 & 0.33 & 0.23 & 0.79 & 2.52 \\
\hline Investment & 8.19 & 1.77 & 1.67 & 2.16 & 6.81 & \\
\hline Hours & 1.20 & 0.28 & 0.26 & 0.35 & 0.97 & 0.27 \\
\hline Capital & 1.62 & 0.35 & 0.34 & 0.39 & 1.38 & 3.14 \\
\hline \multicolumn{7}{|c|}{ D. One-sided Kolmogorov-Smirnov test: p-values } \\
\hline Output & 0.00 & 0.00 & (0.00 & (0.43 & (0.21 & \\
\hline Consumption & 0.00 & 0.00 & 0.00 & 0.36 & 0.16 & \\
\hline Investment & 0.02 & 0.00 & 0.00 & 0.43 & 0.36 & \\
\hline Hours & 0.00 & 0.00 & 0.00 & 0.19 & 0.08 & \\
\hline Capital & 0.00 & 0.00 & 0.00 & 0.24 & 0.14 & \\
\hline
\end{tabular}

Notes: The moments are the averages across the 440 replications of the length of 46 periods. The standard deviations of the mean of the emission reducions are in brackets. The statistics in column 6 are from Fischer and Springborn (2011), Table 6. Panel D corresponds to the Kolmogorov-Smirnov tests of the distributional equivalence of the standard deviations generated by the models with the cap and the tax policies. Low p-value rejects the null in favor of the alternative that the standard deviation is likely to be larger in the case of the tax. 
Table 8: Welfare analysis

\begin{tabular}{|c|c|c|c|c|c|c|c|}
\hline & \multicolumn{5}{|c|}{ Simulations by types of shocks } & \multicolumn{2}{|l|}{ FS (2011) } \\
\hline & None & All & Energy & Oil & En.Int. & Other & Model \\
\hline \multicolumn{8}{|c|}{ A. Welfare costs over the first 30 years } \\
\hline$\phi($ cap $)$ & 0.8309 & 0.8139 & 0.8351 & 0.8352 & 0.8323 & 0.8076 & 0.10 \\
\hline$\phi(\operatorname{tax})$ & 0.8309 & 0.8064 & 0.8296 & 0.8300 & 0.8343 & 0.8081 & 0.09 \\
\hline $\mathrm{p}(\mathrm{U}-\mathrm{eqv})$ & 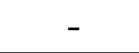 & 0.8920 & 0.0014 & 0.0002 & 0.9998 & 0.9998 & n.a. \\
\hline \multicolumn{8}{|c|}{ B. Welfare costs over the first 100 years } \\
\hline$\phi($ cap $)$ & 0.8665 & 0.8516 & 0.8712 & 0.8713 & 0.8668 & 0.8458 & \\
\hline$\phi(\operatorname{tax})$ & 0.8665 & 0.8448 & 0.8662 & 0.8665 & 0.8689 & 0.8465 & \\
\hline $\mathrm{p}(\mathrm{U}-\mathrm{eqv})$ & 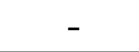 & 0.7982 & 0.0006 & 0.0004 & 0.9990 & 0.9998 & n.a. \\
\hline \multicolumn{8}{|c|}{ C. Welfare cost: years 55 to 100} \\
\hline$\phi($ cap $)$ & 1.0826 & 1.1184 & 1.0849 & 1.0849 & 1.0864 & 1.1109 & 0.81 \\
\hline$\phi(\operatorname{tax})$ & 1.0826 & 1.1120 & 1.0783 & 1.0769 & 1.0891 & 1.1141 & 0.81 \\
\hline $\mathrm{p}(\mathrm{U}$-eqv $)$ & - & 0.8480 & 0.0000 & 0.0000 & 0.9998 & 1.0000 & n.a. \\
\hline
\end{tabular}

Notes: The values of $\phi$ give the percentage reduction in annual consumption from the no policy deterministic steady state needed to replicate the consumption component of the expected utility in the economy with the cap or the tax policy. The entries $\mathrm{p}(\mathrm{U}$-eqv) report the $\mathrm{p}$-value for the Kolmogorov-Smirnov test of the distributional equivalence of the utility levels, computed over the corresponding time horizon, under the cap and the tax. Small p-values imply a rejection of the equivalence. The statistics in the last column are inferred from Fischer and Springborn (2011). 
Table 9: Impact of the emission policy on the distribution of consumption

\begin{tabular}{|c|c|c|c|c|c|}
\hline \multicolumn{6}{|c|}{$\begin{array}{l}\text { A. Kolmogorov-Smirnov test of the distributional } \\
\text { equivalence of consumption: p-values }\end{array}$} \\
\hline \multirow{3}{*}{$\mathrm{p}$, mean } & All & Energy & Oil & Eng.Int. & Other \\
\hline & 0.766 & 0.000 & 0.000 & 0.999 & 0.999 \\
\hline & {$[0.120]$} & {$[0.000]$} & {$[0.000]$} & {$[0.002]$} & {$[0.002]$} \\
\hline \multicolumn{6}{|c|}{ B. Statistics for C: shocks to energy sectors } \\
\hline & mean & med & std & skn $(p-$ & alue) \\
\hline No policy & -0.003 & 0.005 & 0.430 & -0.106 & $0.19)$ \\
\hline Cap & -1.090 & -1.082 & 0.214 & -0.227 & $0.07)$ \\
\hline Tax & -1.087 & -1.078 & 0.390 & -0.116 & $0.18)$ \\
\hline \multicolumn{6}{|c|}{ C. Statistics for C: shocks to oil sector } \\
\hline & mean & med & std & skn $(\mathrm{p}-$ & alue) \\
\hline No policy & -0.002 & 0.007 & 0.414 & -0.118 & $0.17)$ \\
\hline Cap & -1.090 & -1.081 & 0.194 & -0.286 & $0.04)$ \\
\hline Tax & -1.086 & -1.077 & 0.374 & -0.130 & $0.16)$ \\
\hline
\end{tabular}

Notes: Consumption is expressed in percentage deviations from the no policy deterministic steady state. The Kolmogorov-Smirnov test determines if consumption under the cap and the tax is drawn from the same distribution. Panel A reports the mean ( $p$, mean) and the standard deviation (in brackets) of the p-values for this test. The moments are computed for each period of the 440 replications, then averaged across the 46 simulation periods. 
Table 10: Policy impact on the volatility of sectoral gross output

\begin{tabular}{|c|c|c|c|c|c|c|}
\hline & $\overline{\mathrm{COAL}}$ & 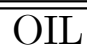 & $\overline{\text { ELEC }}$ & EIN & $\overline{\text { NEIN }}$ & $\overline{\text { SERV }}$ \\
\hline \multicolumn{7}{|c|}{ A. All productivity shocks } \\
\hline Cap & 3.83 & 1.94 & 1.55 & 1.95 & 2.71 & 1.70 \\
\hline Tax & 2.63 & 5.42 & 2.25 & 2.17 & 2.81 & 1.78 \\
\hline KS-test & 0.00 & 0.00 & 0.00 & 0.00 & 0.00 & 0.00 \\
\hline \multicolumn{7}{|c|}{ B. Shocks to energy sectors } \\
\hline Cap & 3.80 & 1.92 & 1.41 & 0.38 & 0.42 & 0.31 \\
\hline Tax & 2.39 & 5.23 & 1.98 & 0.73 & 0.58 & 0.45 \\
\hline KS-test & 0.00 & 0.00 & 0.00 & 0.00 & 0.00 & 0.00 \\
\hline \multicolumn{7}{|c|}{ C. Shocks to the oil sector } \\
\hline Cap & 3.58 & 1.81 & 0.35 & 0.35 & 0.39 & 0.29 \\
\hline Tax & 1.67 & 5.23 & 1.04 & 0.70 & 0.55 & 0.43 \\
\hline KS-test & 0.00 & 0.00 & 0.00 & 0.00 & 0.00 & 0.00 \\
\hline \multicolumn{7}{|c|}{ D. Shocks to the energy-intensive sector } \\
\hline Cap & 0.49 & 0.25 & 0.19 & 0.94 & 0.73 & 0.42 \\
\hline Tax & 0.39 & 0.36 & 0.22 & 0.95 & 0.74 & 0.43 \\
\hline KS-test & 0.00 & 0.00 & 0.00 & 0.63 & 0.74 & 0.52 \\
\hline \multicolumn{7}{|c|}{ E. Shocks to other sectors } \\
\hline Cap & 0.32 & 0.16 & 0.59 & 1.38 & 2.29 & 1.50 \\
\hline $\operatorname{Tax}$ & 0.88 & 0.73 & 0.83 & 1.45 & 2.33 & 1.52 \\
\hline KS-test & 0.00 & 0.00 & 0.00 & 0.00 & 0.42 & 0.25 \\
\hline
\end{tabular}

Notes: The rows Cap and Tax report standard deviations, averaged across 440 replications. KS-test prodives the p-vlaues of the Kolmogorov-Smirnov test for the null hypothesiss that the standard devations under the cap and the tax policies are drawn from the same distribution. Small p-values imply a rejection of the null. 
Table 11: Additional sectoral statistics

\begin{tabular}{rrrrrrr}
\hline \hline & A. Correlation of gross output for COAL and OIL \\
& All & Energy & Oil & En.Int. & Other & U.S. data \\
\hline No policy & 0.57 & 0.53 & 1.00 & -0.72 & 0.86 & 0.40 \\
Cap & -1.00 & -1.00 & -1.00 & -1.00 & -1.00 & - \\
Tax & 0.69 & 0.66 & 1.00 & -0.72 & 0.87 & - \\
\hline \multicolumn{7}{c}{ B. Skewness coefficients: All shocks } \\
\hline \multirow{6}{*}{ Cap } & COAL & OIL & ELEC & EIN & NEIN & SERV \\
& 0.51 & -0.55 & 0.04 & 0.08 & 0.09 & 0.08 \\
& $(0.00)$ & $(0.00)$ & $(0.52)$ & $(0.43)$ & $(0.40)$ & $(0.41)$ \\
Tax & 0.03 & 0.04 & 0.04 & 0.09 & 0.10 & 0.08 \\
& $(0.47)$ & $(0.52)$ & $(0.51)$ & $(0.44)$ & $(0.38)$ & $(0.42)$ \\
\hline \multicolumn{7}{c}{ C. Skewness coefficients: Oil shocks } \\
\hline Cap & 0.56 & -0.60 & 0.08 & -0.30 & -0.14 & -0.20 \\
& $(0.00)$ & $(0.00)$ & $(0.44)$ & $(0.11)$ & $(0.27)$ & $(0.21)$ \\
Tax & -0.11 & 0.00 & -0.16 & -0.08 & -0.11 & -0.12 \\
& $(0.37)$ & $(0.51)$ & $(0.26)$ & $(0.39)$ & $(0.33)$ & $(0.33)$ \\
\hline \hline
\end{tabular}

Notes: The moments are computed for each period of 440 replications, then averaged across the 46 periods. The values in parantheses are the average p-values of the null hypothesis that the distribution is symmetric. 
Figure 1 Probability density functions of consumption
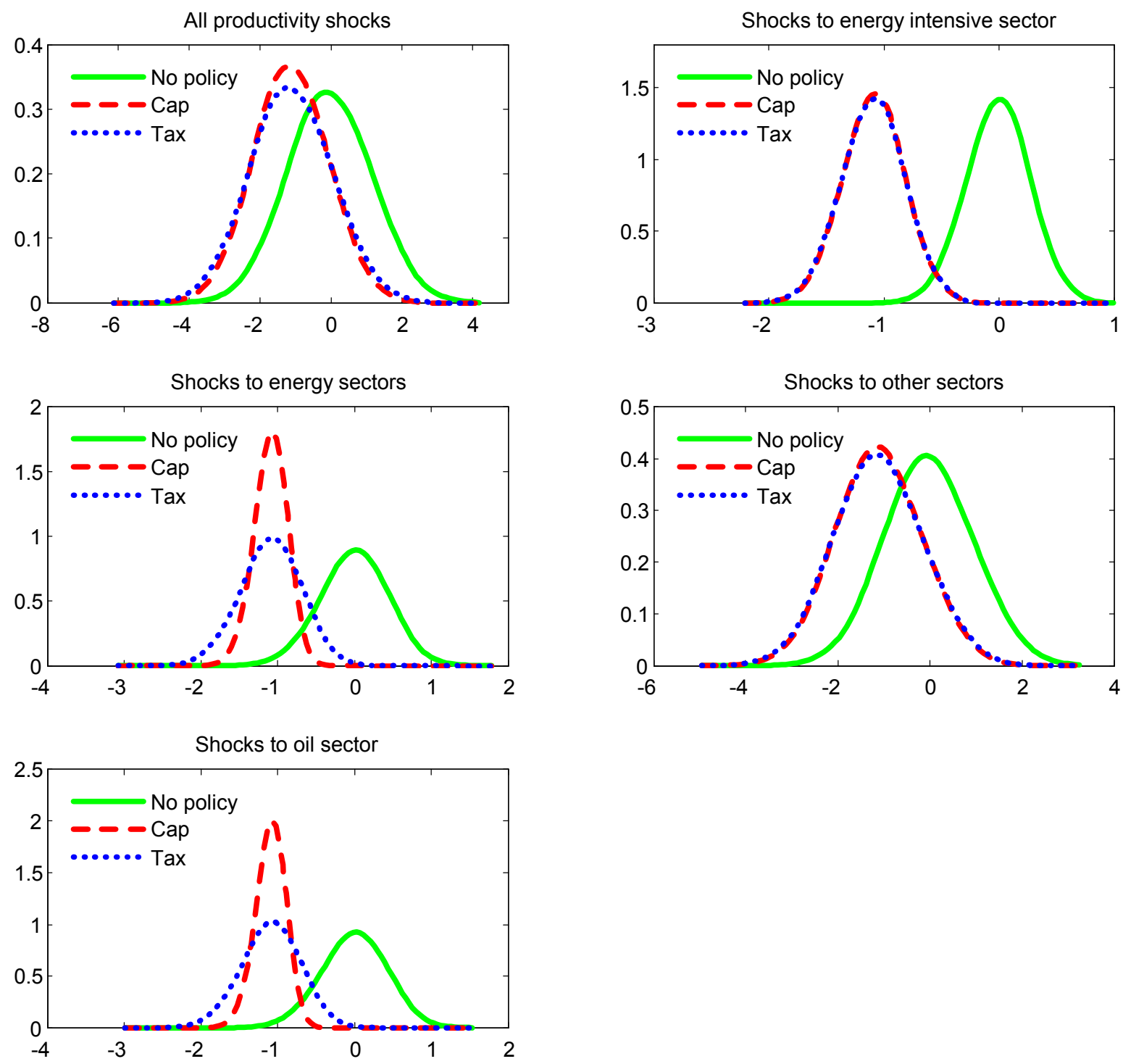

Notes: Consumption is expressed in percentage changes from the no policy deterministic steady state. The curves are kernel densities of 440 consumption realizations for each simulation period, averaged across the 46 simulation periods. 
Figure 2 Probability density functions of gross output: simulations with productivity shocks in the OIL sector
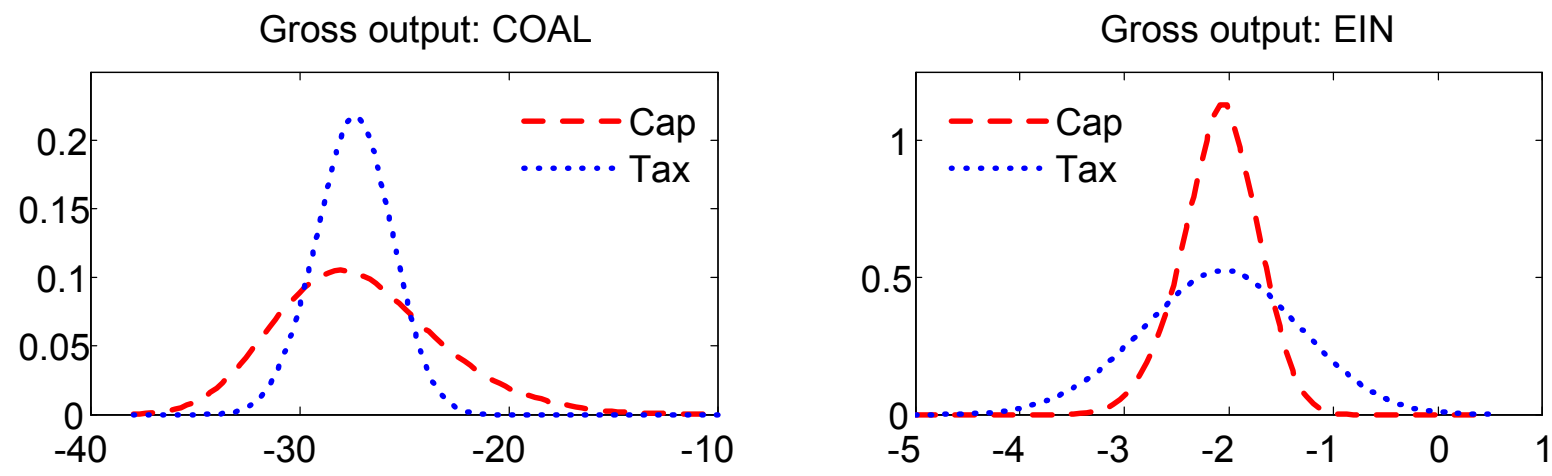

Gross output: OIL

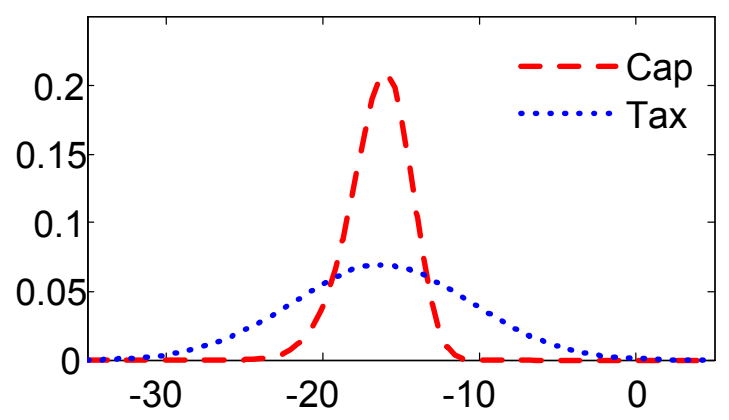

Gross output: NEIN

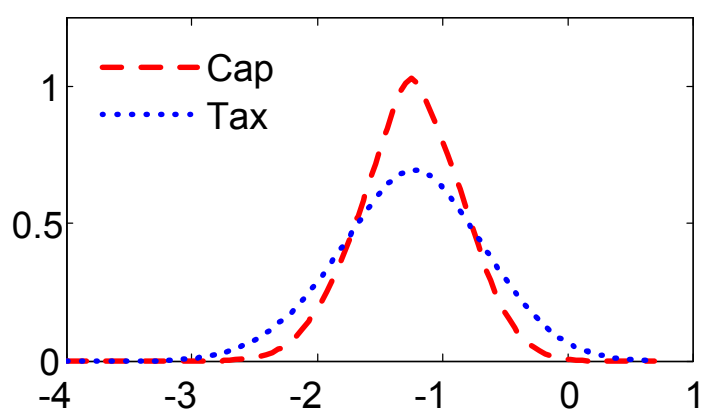

Gross output: ELEC
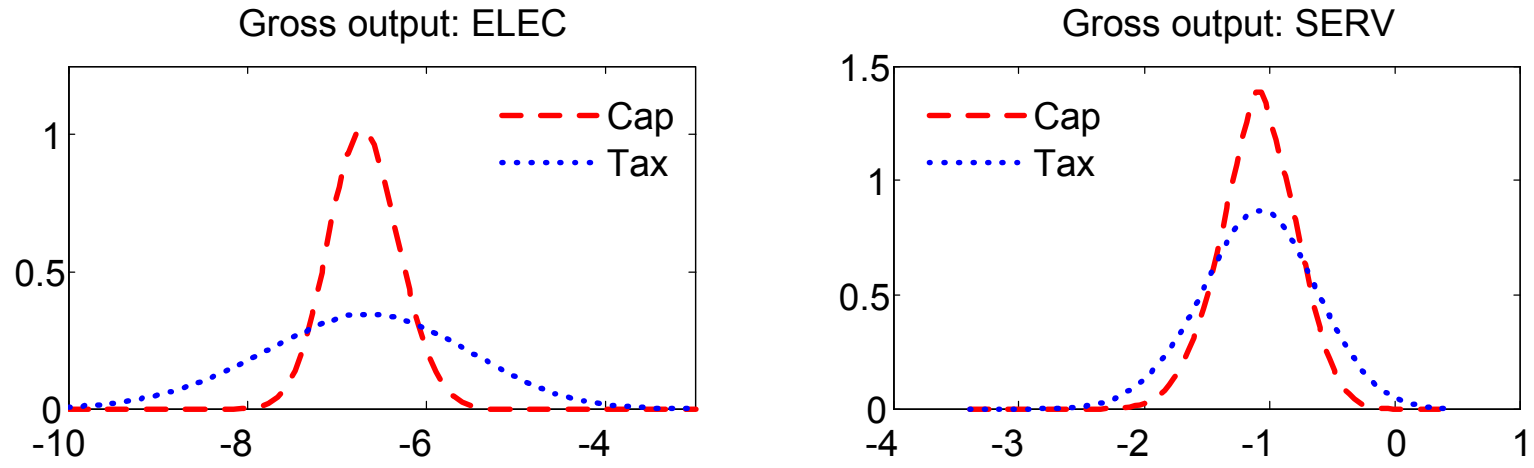

Notes: Output is expressed in percentage changes from the no policy deterministic steady state. The curves are kernel densities of 440 output realizations for each simulation period, averaged across the 46 simulation periods. 


\section{Technical Appendix}

This appendix provides details about the model specification, aggregation of empirical and theoretical data, and welfare calculations.

\subsection{Detailed description of the model}

\subsubsection{The firm's problem}

The representative firm in sector $j$ operates constant returns to scale production technology that uses capital $K_{j t}$, labor $L_{j t}$ and intermediate inputs $M_{j t}^{i}, i=1, \ldots, N$. The superscript $i$ in the intermediate input indicates sector $i$ that produced the input, while the subscript $j$ denotes the sector that uses this input. In addition to the general index $j$, the sectors are also referred by their abbreviated names: coal, oil, elec, ein, nein, serv. Output $Y_{j t}$ of good $j$ in period $t$ is produced according to

$$
Y_{j t}=F\left(K L E\left\{A_{j t}, K_{j t}, L_{j t}, E\left[F S\left(M_{j t}^{\text {coal }}, M_{j t}^{\text {oil }}\right), M_{j t}^{\text {elec }}\right]\right\}, M_{j t}^{\text {ein }}, M_{j t}^{\text {nein }}, M_{j t}^{\text {serv }}\right) .
$$

The representative firm in sector $j$ maximizes profits

$$
\max P_{j t}^{y} Y_{j t}-R_{t} K_{j t}-w_{j t} L_{j t}-\sum_{i=1}^{N} p_{i t} M_{j t}^{i}
$$

subject to the following nestlings of the production function:

$$
\begin{aligned}
Y_{j t} & =\min \left\{\frac{1}{a_{j}^{k l e}} K L E_{j t}, \frac{M_{j t}^{\text {ein }}}{a_{j}^{\text {ein }}}, \frac{M_{j t}^{\text {nein }}}{a_{j}^{\text {nein }}}, \frac{M_{j t}^{\text {serv }}}{a_{j}^{\text {serv }}}\right\}, \\
K L E_{j t} & =\operatorname{KLE}\left(A_{j t}, K_{j t}, L_{j t}, E_{j t}\right)=A_{j t} K_{j t}^{\alpha_{K j}} L_{j t}^{\alpha_{L j}} E_{j t}^{1-\alpha_{K j}-\alpha_{L j}},
\end{aligned}
$$

where

$$
A_{j t}=\bar{A}_{j} Z_{j t}, \quad Z_{j t}=\rho_{j} \ln Z_{j, t-1}+\varepsilon_{j t}
$$

and

$$
\begin{aligned}
E_{j t} & =E\left(F S_{j t}, M_{j t}^{e l e c}\right)=A_{j}^{E}\left[a_{E j}\left(F S_{j t}\right)^{\frac{\sigma_{E j}-1}{\sigma_{E j}}}+\left(1-a_{E j}\right)\left(M_{j t}^{e l e c}\right)^{\frac{\sigma_{E j}-1}{\sigma_{E j}}}\right]^{\frac{\sigma_{E j}}{\sigma_{E j}-1}}, \\
F S_{j t} & =F S\left(M_{j t}^{c o a l}, M_{j t}^{\text {oil }}\right)=A_{j}^{F}\left[a_{F j}\left(M_{j t}^{c o a l}\right)^{\frac{\sigma_{F j}-1}{\sigma_{F j}}}+\left(1-a_{F j}\right)\left(M_{j t}^{o i l}\right)^{\frac{\sigma_{F j}-1}{\sigma_{F j}}}\right]^{\frac{\sigma_{F j}}{\sigma_{F j}-1}} .
\end{aligned}
$$

We solve the problem by examining the cost minimization problems at every four levels of production nesting. In this section we provide the first order conditions characterizing the optimal choice of the firm. The auxiliary price indices $P_{j t}^{K L E}, P_{j t}^{E} P_{j t}^{F S}$ correspond to the index prices of the cost minimization problems. The price $p_{j t}$ is the user price of the good produced in sector $j$, while the price of output $P_{j t}^{y}$ is the after tax producer price:

$$
P_{j t}^{y}=\left(1-\tau_{j}\right) p_{j t}
$$


Gross output level Gross output for sector $j$ and its price are

$$
\begin{aligned}
Y_{j t} & =\min \left\{\frac{1}{a_{j}^{k l e}} K L E_{j t}, \frac{M_{j t}^{e i n}}{a_{j}^{\text {ein }}}, \frac{M_{j t}^{\text {nein }}}{a_{j}^{\text {nein }}}, \frac{M_{j t}^{\text {serv }}}{a_{j}^{\text {serv }}}\right\}, \\
P_{j t}^{y} & =a_{j}^{k l e} P_{j t}^{k l e}+a_{j}^{e i n} M_{j t}^{\text {ein }}+a_{j}^{\text {nein }} M_{j t}^{n e i n}+a_{j}^{\text {serv }} M_{j t}^{\text {serv }} .
\end{aligned}
$$

The demands for non-energy intermediate inputs and for the KLE index are proportional to gross output in sector $j$,

$$
\begin{aligned}
K L E_{j t} & =a_{j}^{k l e} Y_{j t}, \\
M_{j t}^{i} & =a_{j}^{i} Y_{j t}, i \in\{\text { ein, nein, serv }\} .
\end{aligned}
$$

KLE-output level The KLE output and its price are given by

$$
\begin{aligned}
K L E_{j t} & =K L E\left(A_{j t}, K_{j t}, L_{j t}, E_{j t}\right)=A_{j t} K_{j t}^{\alpha_{K j}} L_{j t}^{\alpha_{L j}} E_{j t}^{1-\alpha_{K j}-\alpha_{L j}}, \\
P_{j t}^{k l e} & =\frac{1}{A_{j t}}\left[\frac{R_{t}}{\alpha_{K j}}\right]^{\alpha_{K j}}\left[\frac{w_{j t}}{\alpha_{L j}}\right]^{\alpha_{L j}}\left[\frac{P_{j t}^{e}}{1-\alpha_{K j}-\alpha_{L j}}\right]^{1-\alpha_{K j}-\alpha_{L j}} .
\end{aligned}
$$

The demands for capital, labor and energy inputs for sector $j$ are

$$
\begin{aligned}
K_{j t} & =\frac{\alpha_{K_{j}} P_{j t}^{K L E} K L E_{j t}}{R_{t}}, \\
L_{j t} & =\frac{\alpha_{L_{j}} P_{j t}^{K L E} K L E_{j t}}{w_{j t}}, \\
E_{j t} & =\frac{\left(1-\alpha_{K j}-\alpha_{L j}\right) P_{j t}^{k l e}}{P_{j t}^{e}} K L E_{j t} .
\end{aligned}
$$

Energy production level The optimal quantity of the energy input for sector $j$ and its price are given by

$$
\begin{aligned}
E_{j t} & =E\left(F S_{j t}, M_{j t}^{\text {elec }}\right)=A_{j}^{E}\left[a_{E j}\left(F S_{j t}\right)^{\frac{\sigma_{E j}-1}{\sigma_{E j}}}+\left(1-a_{E j}\right)\left(M_{j t}^{e l e c}\right)^{\frac{\sigma_{E j}-1}{\sigma_{E j}}}\right]^{\frac{\sigma_{E j}}{\sigma_{E j}-1}} \\
P_{j t}^{e} & =\frac{1}{A_{j}^{E}}\left[\left(\alpha_{E_{j}}\right)^{\sigma_{E j}}\left(P_{j t}^{f s}\right)^{1-\sigma_{E j}}+\left(1-\alpha_{E_{j}}\right)^{\sigma_{E j}}\left(p_{\text {elec }, t}\right)^{1-\sigma_{E j}}\right]^{\frac{1}{1-\sigma_{E j}}} .
\end{aligned}
$$

The demands for electricity and fossils by sector $j$ are

$$
\begin{aligned}
F S_{j t} & =\left(A_{j}^{E}\right)^{\sigma_{E j}-1}\left[\frac{\alpha_{F_{j}} P_{j t}^{e}}{P_{j t}^{f s}}\right]^{\sigma_{E j}} E_{j t}, \\
M_{j t}^{\text {elec }} & =\left(A_{j}^{E}\right)^{\sigma_{E j}-1}\left[\frac{\left(1-\alpha_{F_{j}}\right) P_{j t}^{e}}{p_{\text {elec }, t}}\right]^{\sigma_{E j}} E_{j t .}
\end{aligned}
$$


Fossil production level The optimal quantity of fossils for sector $j$ and its price are

$$
\begin{aligned}
F S_{j t} & =F S\left(M_{j t}^{c o a l}, M_{j t}^{o i l}\right)=A_{j}^{F}\left[a_{F j}\left(M_{j t}^{c o a l}\right)^{\frac{\sigma_{F j}-1}{\sigma_{F j}}}+\left(1-a_{F j}\right)\left(M_{j t}^{o i l}\right)^{\frac{\sigma_{F j}-1}{\sigma_{F j}}}\right]^{\frac{\sigma_{F j}}{\sigma_{F j}-1}} \\
P_{j t}^{f s} & \left.=\frac{1}{A_{j}^{F}}\left[\left(a_{F j}\right)^{\sigma_{F j}}\left(p_{c o a l, t}\right)^{\left(1-\sigma_{F j}\right.}\right)+\left(1-a_{F j}\right)^{\sigma_{F j}}\left(p_{o i l, t}\right)\left(1-\sigma_{F j}\right)\right]^{\frac{1}{1-\sigma_{F j}}} .
\end{aligned}
$$

The demand for coal and oil and gas inputs by sector $j$ are

$$
\begin{aligned}
M_{j t}^{\text {coal }} & =\left(A_{j}^{F}\right)^{\sigma_{F j}-1}\left[\frac{a_{F j} P_{j t}^{f s}}{p_{c o a l, t}}\right]^{\sigma_{F_{j}}} F S_{j t}, \\
M_{j t}^{o i l} & =\left(A_{j}^{F}\right)^{\sigma_{F j}-1}\left[\frac{\left(1-a_{F j}\right) P_{j t}^{f s}}{p_{o i l, t}}\right]^{\sigma_{F_{j}}} F S_{j t} .
\end{aligned}
$$

The prices $p_{c o a l, t}$ and $p_{o i l, t}$ are the user prices of coal, and oil and gas.

The relative demands for fossil fuels are

$$
\frac{M_{j t}^{c o a l}}{M_{j t}^{o i l}}=\left[\frac{a_{F j}}{\left(1-a_{F j}\right)} \frac{p_{o i l, t}}{p_{c o a l, t}}\right]^{\sigma_{F j}}
$$

\subsubsection{The household's problem}

The representative household chooses the sequences of consumption, hours worked and investment for every $j=1, \ldots, N,\left\{c_{j t}, h_{j t}, x_{j t}\right\}_{t=0}^{\infty}$ to maximize the expected utility

$$
E_{0} \sum_{t=0}^{\infty} \beta^{t} U\left(C_{t}, 1-H_{t}\right), \beta \in(0,1)
$$

subject to the budget constraint

$$
\sum_{j=1}^{N} p_{j t} c_{j t}+\sum_{j=1}^{N} p_{j t} x_{j t}=\left(1-\tau_{h}\right) \sum_{j=1}^{N} w_{j t} h_{j t}+\left(1-\tau_{k}\right) R_{t} K_{t}+T_{t}
$$

the capital accumulation equation

$$
\begin{aligned}
K_{t+1} & =(1-\delta) K_{t}+X_{t}, \delta \in(0,1), t \geq 0 \\
K_{0} & >0 \text { is given }
\end{aligned}
$$


the definitions of the consumption, hours, and investment aggregators

$$
\begin{aligned}
& C_{t}=A_{c} \prod_{j \in N_{c}}\left(c_{j t}\right)^{\xi_{j}}, A_{c}>0, \xi_{j} \in(0,1), \sum_{j \in N_{c}} \xi_{j}=1 \\
& H_{t}=A_{h}\left[\sum_{j=1}^{N} \eta_{j} h_{j t}^{(\zeta+1) / \zeta}\right]^{\zeta /(\zeta+1)}, A_{h}>0, \eta_{j} \in(0,1), \sum_{j=1}^{N} \eta_{j}=1 \\
& X_{t}=A_{x} \prod_{j \in N_{x}}\left(x_{j t}\right)^{\gamma_{j}}, A_{x}>0, \quad \gamma_{j} \in(0,1), \sum_{j \in N_{x}} \gamma_{j}=1
\end{aligned}
$$

and a constraint ruling out Ponzi schemes (unlimited borrowing)

$$
\begin{aligned}
\lim _{n \rightarrow \infty} \frac{1}{\Pi_{i=1}^{n-1}\left(1+r_{t+i}\right)} K_{t+1+n} & \geq 0, t \geq 0 \\
1+r_{t+1} & =\frac{\left(1-\tau_{k}\right) R_{t+1}+Q_{t+1}}{Q_{t}} \frac{P_{t}}{P_{t+1}} .
\end{aligned}
$$

The sets of goods $N_{c}$ and $N_{x}$ are the subsets of all available $N$ goods. The values of consumption, investment and hours are constraint as follows

$$
c_{j t} \geq 0, x_{j t} \geq 0, h_{j t} \in[0,1] .
$$

The instantaneous utility function takes the form

$$
U\left(C_{t}, 1-H_{t}\right)=\ln C_{t}+\chi \ln \left(1-H_{t}\right)
$$

To find the demand for consumption goods, we first find the optimal division of $C_{t}$ among individual consumption goods $c_{j t}$ for a given level of expenditures $Z_{t}$ in period $t$. This is done by maximizing the level of consumption for a given level of consumption expenditure. That is, we choose $c_{j t}$ to maximize

$$
\max A_{c} \prod_{j \in N_{c}}\left(c_{j t}\right)^{\xi_{j}}
$$

subject to

$$
\sum_{j=1}^{N} p_{j t} c_{j t}=Z_{t} .
$$

With the Cobb-Douglas aggregator for consumption, demand for good produced in sector $j$ is a constant fraction of total consumption expenditures,

$$
\begin{aligned}
c_{j t} & =\xi_{j} \frac{Z_{t}}{p_{j t}} \text { if } j \in N_{c}, \\
c_{j t} & =0 \text { if } j \notin N_{c} .
\end{aligned}
$$

We define the consumption-based price index $P_{t}$ as the minimum expenditure $Z_{t}=$ 
$\sum_{j=1}^{N} p_{j t} c_{j t}$ such that given $P_{t}, C_{t}=C\left(c_{1 t}, c_{2 t}, \ldots, c_{N t}\right)=1$. This index measures the lowest level of expenditures that buys a unit of the consumption index.

The expressions in (20) show the demands for $c_{j t}$ that maximize $C_{t}$ given expenditures $Z_{t}$. The highest value of the index $C_{t}$, given $Z_{t}$, is found by substituting those demands in the definition (19):

$$
A_{c} \prod_{j \in N_{c}}\left(\xi_{j} \frac{Z_{t}}{p_{j t}}\right)^{\xi_{j}}=Z_{t} A_{c} \prod_{j \in N_{c}}\left(\frac{\xi_{j}}{p_{j t}}\right)^{\xi_{j}} .
$$

Since $P_{t}$ is defined as the minimum expenditure such that $C_{t}=1$, the expression for $P_{t}$ is then given by

$$
P_{t}=\frac{1}{A_{c}} \prod_{j \in N_{c}}\left(\frac{p_{j t}}{\xi_{j}}\right)^{\xi_{j}} .
$$

A similar approach yields the expressions for investment demands and the investment price index that appear in the text.

$$
\begin{aligned}
x_{j t} & =\gamma_{j} \frac{Q_{t} X_{t}}{p_{j t}} \text { for } j \in N_{x}, x_{j t}=0 \text { for } j \notin N_{x}, \\
Q_{t} & =\frac{1}{A_{x}} \prod_{j \in N_{x}}\left(\frac{p_{j t}}{\gamma_{j}}\right)^{\gamma_{j}} .
\end{aligned}
$$

Let now $Z_{t}$ represent total labor income in period $t$. To find the allocations of hours among the sectors, we find the lowest level of hours that yields this income. That is, we choose $h_{j t}$ to minimize

$$
\min A_{h}\left[\sum_{j=1}^{N} \eta_{j} h_{j t}^{(\zeta+1) / \zeta}\right]^{\zeta /(\zeta+1)}
$$

subject to

$$
\sum_{j=1}^{N} w_{j t} h_{j t}=Z_{t}
$$

The first order optimality conditions imply the following labor supply for sector $j$ :

$$
h_{j t}=\left(\frac{w_{j t}}{\eta_{j}}\right)^{\zeta} \frac{Z_{t}}{\sum_{j=1}^{N}\left(\eta_{j}\right)^{-\zeta}\left(w_{j t}\right)^{1+\zeta}} .
$$

We define aggregate wage $W_{t}$ as the maximum labor income $Z_{t}=\sum_{j=1}^{N} w_{j t} h_{j t}$ such that given $W_{t}, H_{t}=H\left(h_{1 t}, h_{2 t}, \ldots, c_{N t}\right)=1$. Given the expressions in (21) for the labor supply 
$h_{j t}$, the wage is computed from

$$
A_{h}\left[\sum_{j=1}^{N} \eta_{j} h_{j t}^{(\zeta+1) / \zeta}\right]^{\zeta /(\zeta+1)}=Z_{t} A_{h}\left[\sum_{j=1}^{N}\left(\eta_{j}\right)^{-\zeta}\left(w_{j t}\right)^{1+\zeta}\right]^{-1 /(1+\zeta)}
$$

Since $W_{t}$ is defined as the maximum labor income such that $H_{t}=1$, the expression for $W_{t}$ is then given by

$$
W_{t}=\frac{1}{A_{h}}\left[\sum_{j=1}^{N}\left(\eta_{j}\right)^{-\zeta}\left(w_{j t}\right)^{1+\zeta}\right]^{1 /(1+\zeta)} .
$$

Using $Z_{t}=W_{t} H_{t}$ and the definition of the wage $W_{t}$, the sectoral labor supply in (21) is expressed as

$$
\begin{aligned}
h_{j t} & =\left(\frac{w_{j t}}{\eta_{j}}\right)^{\zeta} \frac{A_{h}^{1+\zeta}}{\left\{A_{h}\left[\sum_{j=1}^{N}\left(\eta_{j}\right)^{-\zeta}\left(w_{j t}\right)^{1+\zeta}\right]^{1 /(1+\zeta)}\right\}^{1+\zeta}} W_{t} H_{t}, \\
\text { or } h_{j t} & =\frac{1}{A_{h}^{1+\zeta}}\left(\frac{w_{j t}}{\eta_{j} W_{t}}\right)^{\zeta} H_{t}
\end{aligned}
$$

Given the optimal allocations for individual consumption and investment goods, optimal hours for every sector $j$, the definitions of quantity and price aggregates, the household's problem can be redefined in terms of aggregates. The household chooses $\left\{C_{t}, H_{t}, X_{t}, K_{t+1}\right\}_{t=0}^{\infty}$, taken as given the prices $\left\{P_{t}, W_{t}, Q_{t}, R_{t}\right\}_{t=0}^{\infty}$ and the taxes $\tau_{h}, \tau_{k}, T_{t}$, to maximize

$$
E_{0} \sum_{t=0}^{\infty} \beta^{t} U\left(C_{t}, 1-H_{t}\right)
$$

subject to the budget constraint and the capital accumulation equation

$$
\begin{aligned}
P_{t} C_{t}+Q_{t} X_{t} & =\left(1-\tau_{h}\right) W_{t} H_{t}+\left(1-\tau_{k}\right) R_{t} K_{t}+T_{t}, \\
K_{t+1} & =(1-\delta) K_{t}+X_{t} .
\end{aligned}
$$

This is a standard problem. The first order conditions, in addition to (22), (23), include the transversality condition

$$
\lim _{t \rightarrow \infty} \beta^{t} \lambda_{t} K_{t+1}=0, \lambda_{t}=\frac{U_{C}\left(C_{t}, 1-H_{t}\right)}{P_{t}}
$$

and two equations describing the trade-offs between consumption and leisure, and consumption and saving. The first equation equates the marginal rate of substitution between consumption and leisure to the market price of leisure. The intertemporal Euler equation 
defines the optimal consumption allocation over time.

$$
\begin{aligned}
\frac{\chi C_{t}}{1-H_{t}} & =\left(1-\tau_{h}\right) \frac{W_{t}}{P_{t}}, t \geq 0, \\
\frac{1}{C_{t}} & =\beta E_{t}\left[\frac{1}{C_{t+1}} \frac{\left[\left(1-\tau_{k}\right) R_{t+1}+(1-\delta) Q_{t+1}\right] / P_{t+1}}{Q_{t} / P_{t}}\right], t \geq 0 .
\end{aligned}
$$

\subsubsection{The government}

The government is defined by the budget constraint. In the absence of the environmental regulations, the budget constraint is

$$
T_{t}=\sum_{j=1}^{N} \tau_{j} p_{j t} Y_{j t}+\tau_{h} W_{t} H_{t}+\tau_{k} R_{t} K_{t}-\sum_{j=1}^{N} p_{j t} G_{j t} .
$$

\subsubsection{Competitive equilibrium}

No emissions policy A perfectly competitive equilibrium consists of sector-specific quantities $\left\{c_{j t}, x_{j t}, h_{j t}, Y_{j t}, K_{j t}, L_{j t}, M_{j t}, K L E_{j t}, E_{j t}, F S_{j t}\right\}_{t=0}^{\infty}, M_{j t}=\left\{M_{j t}^{1}, \ldots, M_{j t}^{N}\right\}$ and prices $\left\{w_{j t}, p_{j t}, P_{j t}^{y}\right\}_{t=0}^{\infty}, j=1, . ., N$, aggregate quantities $\left\{C_{t}, H_{t}, X_{t}, K_{t+1}\right\}_{t=0}^{\infty}$ and prices $\left\{P_{t}, Q_{t}\right.$, $\left.W_{t}, R_{t}\right\}_{t=0}^{\infty}$, price indices for cost minimization $\left\{P_{j t}^{K L E}, P_{j t}^{E}, P_{j t}^{F S}\right\}_{t=0}^{\infty}$ and tax instruments $\left\{T_{t}, \tau_{h}, \tau_{k}\right\}_{t=0}^{\infty}$ such that given the process for the productivity shocks (18), the exogenous government consumption $\left\{G_{1 t}, \ldots, G_{N t}\right\}_{t=0}^{\infty}$ and the initial stock of capital $K_{0}$, the following conditions are satisfied:

1. Firms solve the profit maximization problem, taking prices as given;

2. Households solve the utility maximization problem, taking prices as given;;

3. The government balances its budget (24) in every period $t \geq 0$;

4. Capital, labor and goods markets clear in every period $t \geq 0$ :

$$
\begin{aligned}
K_{t} & =\sum_{j=1}^{N} K_{j t}, h_{j t}=L_{j t}, j=1, \ldots, N, \\
Y_{j t} & =c_{j t}+x_{j t}+G_{j t}+\sum_{i=1}^{N} M_{j t}^{i}, j=1, \ldots, N .
\end{aligned}
$$

\subsection{Industry classification: adjustments to the BEA data}

Table 1 of the paper gives our classification of the industries from the Jorgenson's data set and the input-output (I-O) accounts from the BEA. Several adjustments had to be applied to the BEA data to achieve a concordance between the two data sets. 
The Jorgenson's data set provides data for coal mining (3), crude oil and gas extraction (4), petroleum refining (6) and gas utilities (31). The numbers in the parentheses indicate the industry codes in the data set. The BEA annual I-O tables do not provide separate information on coal mining [212100], natural gas distribution [221200], and electric power generation, transmission, and distribution [221100]. Instead, these industries are included into broader categories of mining, except oil and gas [212] and utilities [22]. The numbers in brackets indicate the NAICS industry codes.

To construct the statistics for the industries of our interest ([212100], [221200] and [221100]), we used the 2002 benchmark I-O tables. The information in these tables are given at the 6-digit level of NAICS codes. We computed the shares of the industries [212100], [221200] and [221100] in the broader aggregates [212] and [22]. Assuming that the shares were constant throughout the sample period, we constructed the relevant statistics for the separates components of [212] and [22].

The rest of the components of Mining [212] included iron ore mining; gold, silver, and other metal ore mining; copper, nickel, lead, and zinc mining; stone mining and quarrying; sand, gravel, clay, and ceramic and refractory minerals mining and quarrying; other nonmetallic mineral mining and quarrying. These components were placed into our energyintensive sector. The water, sewage and other systems [221300] components of utilities [22] was added to services.

Another adjustment was made to the BEA data to compatibility with the Jorgenson's data set. The Jorgenson's data set include only government enterprises (35). By contrast, the government in the BEA includes not only government enterprises, but also Federal defense and non-defense services, state and local government services, including public education, hospitals, highway government services, park and recreation and other.

\subsection{Aggregation in the data and in the model}

This section explains the procedure for aggregating prices and quantities corresponding to the six sectors of our model. Since the aggregation uses the Törnqvist approach, this approach is defined first. In addition, this section provides details about the construction of sectoral and aggregate outputs.

\subsubsection{The Törnqvist approach}

The Törnqvist aggregate of multiple series (also known as a translog index) is computed on the basis of prices and quantities. The Törnqvist index is used by BLS in constructing aggregates of capital and labor inputs and computing the multifactor productivity measures. The index is a discrete time approximation of a Divisia index computed by Horvath (2000) and Kim and Kim (2006). The index is calculated as a weighted average of growth rates of the components. The weights are allowed to vary every period, and are defined as the mean of the relative compensation shares of the components in two adjacent years.

Let $P_{i, t}$ and $X_{i, t}$ define the price and quantity of item $i$ in period $t$. Let the growth rate be approximated by the first difference of the natural logarithm, $\Delta X_{i, t}=\ln X_{i, t}-\ln X_{i, t-1}$. 
The growth rate of the quantity index $Y_{t}$ is computed as follows

$$
\Delta Y_{t}=\Sigma_{i}\left(\frac{s_{i, t}+s_{i, t-1}}{2}\right) \Delta X_{i, t}
$$

where the weight $s_{i, t}=\frac{P_{i, t} X_{i, t}}{\Sigma_{i} P_{i, t} X_{i, t}}$ is the share of item $i$ in the total expenditures in period $t$. Given he growth rates, the level of the quantity index $Y_{t}$ is pinned down at the base period. For example, with the given value $Y_{0}$, the consecutive periods are chained as

$$
Y_{t+1}=Y_{t} \exp \left(\Delta Y_{t}\right)
$$

The nominal value of the quantity index $Y_{t}$ is equal to $\Sigma_{i} P_{i, t} X_{i, t}$, the sum of the values of the components $X_{i, t}$. The corresponding price index $P_{t}$ is defined as a ratio of the value of the inputs to the Törnqvist quantity index. ${ }^{14}$

\subsubsection{Sectoral series based on the Jorgenson's data}

The Jorgenson's data set contains comprehensive information on the industry-level prices and quantities of gross output and various inputs. The following variables are used to construct the empirical analogues of our theoretical sectors: quantity of industry output 1996 prices (qout) price of industry output (po), quantity of capital input (qktemp), quantity of labor input (qltemp) quantity of intermediate use of Energy (qe), quantity of intermediate use of Materials (qm), price of capital input (pk), price of labor input (pl), price of intermediate use of Energy (pe), price of intermediate use of Materials (pm). The names of the variable in the Jorgenson's data set is indicated in the parentheses. The sectoral aggregates for gross output, capital, labor, energy and materials are constructed as the Törnqvist indices. The Törnqvist approach is further used to construct the aggregate series for the U.S. economy.

Let $Y_{j, t}$ and $M_{j, t}$ now denote the gross output and the materials in sector $j$ a,and $P_{j, t}$ and $P_{j, t}^{M}$ be their corresponding price indices. Nominal sectoral KLE output in sector $j$ is computed as the difference between the value of gross output in that sector and the cost of the materials used in the production as in

$$
V K L E_{j, t}=P_{j, t} Y_{j, t}-P_{j, t}^{M} M_{j, t}
$$

The growth rate of $K L E_{j, t}$ is defined as the Törnqvist index of sectoral output growth minus the growth rate of the materials as in

$$
\Delta K L E_{j, t}=\frac{1}{2}\left(\frac{P_{j, t} Y_{j, t}}{V K L E_{j, t}}+\frac{P_{j, t-1} Y_{j, t-1}}{V K L E_{j, t-1}}\right) \Delta Y_{j, t}-\frac{1}{2}\left(\frac{P_{j, t}^{M} M_{j, t}}{V K L E_{j, t}}+\frac{P_{j, t-1}^{M} M_{j, t-1}}{V K L E_{j, t-1}}\right) \Delta M_{j, t}
$$

\footnotetext{
${ }^{14}$ See p. 5 in Jorgenson et al. (1987).
} 
The level of the $K L E_{j, t}$ is pinned down with

$$
\begin{aligned}
K L E_{j, t+1} & =K L E_{j, t} \exp \left(\Delta K L E_{j, t}\right), \\
K L E_{j, 0} & =1 .
\end{aligned}
$$

The level of $K L E$ is further normalized so that its values in 1996 is equal to the nominal value. That is, $K L E_{j, t}$ is expressed in constant 1996 prices.

\subsubsection{Construction of value-added output}

Sectoral and aggregate value added for the empirical data and the model are constructed using exactly the same procedure. For concreteness, this subsection uses the notation from the paper to denote theoretical series, and the notation from the Jorgenson's data set to denote empirical series.

In nominal terms, sectoral value added are defined as the difference between the value of gross output and the cost of the intermediate inputs.

$$
\begin{array}{ll}
\text { Model: } & p_{j t}^{v} V_{j t}=P_{j t}^{y} Y_{j t}-\sum_{i=1}^{N} p_{i t} M_{j t}^{i}, \\
\text { Data }: & p_{j t}^{v} V_{j t}=\mathrm{po}_{j t} \mathrm{qout}_{j t}-\mathrm{pe}_{j t} \mathrm{qe}_{j t}-\mathrm{pm}_{j t} \mathrm{qm}_{j t}
\end{array}
$$

Aggregate nominal value added is the sum over all sectoral nominal value added:

$$
p_{t}^{v} V_{t}=\sum_{j=1}^{N} p_{j t}^{v} V_{j t}
$$

Sectoral value-added growth rate in sector $j$ is defined as the Törnqvist index of sectoral output growth minus the growth rate of the materials. In the model, the growth rate is equal to

$$
\Delta V_{j, t}=\frac{1}{2}\left(\frac{p_{j t} Y_{j t}}{p_{t}^{v} V_{t}}+\frac{p_{j, t-1} Y_{j, t-1}}{p_{t}^{v} V_{t-1}}\right) \Delta Y_{j, t}-\frac{1}{2} \sum_{i=1}^{N}\left(\frac{p_{i t} M_{j t}^{i}}{p_{t}^{v} V_{t}}+\frac{p_{i, t-1} M_{j, t-1}^{i}}{p_{t}^{v} V_{t-1}}\right) \Delta M_{j t}^{i} .
$$

In the data, the growth rate is computed as

$$
\begin{aligned}
& \Delta V_{j, t}=\frac{1}{2}\left(\frac{\mathrm{po}_{j i} \mathrm{qout}_{j t}}{p_{t}^{v} V_{t}}+\frac{\mathrm{po}_{j, i-1} \mathrm{qout}_{j, t-1}}{p_{t}^{v} V_{t-1}}\right) \Delta \text { qout }_{j t} \\
& -\frac{1}{2}\left(\frac{\mathrm{pe}_{j t} \mathrm{qe}_{j t}}{p_{t}^{v} V_{t}}+\frac{\mathrm{pe}_{j, t-1} \mathrm{qe}_{j, t-1}}{p_{t}^{v} V_{t-1}}\right) \Delta \mathrm{qe}_{j t}-\frac{1}{2}\left(\frac{\mathrm{pm}_{j t} \mathrm{qm}_{j t}}{p_{t}^{v} V_{t}}+\frac{\mathrm{pm}_{j, t-1} \mathrm{qm}_{j, t-1}}{p_{t}^{v} V_{t-1}}\right) \Delta \mathrm{qm}_{j t}
\end{aligned}
$$

The level of the $V_{j t}$ is pinned down following $V_{j, t+1}=V_{j t} \exp \left(\Delta V_{j t}\right)$. The initial value is set to $V_{j, 0}=1$ for the data. In the model, the initial value is set to $V_{j, 0}=\left(P_{j}^{y}\right)^{*} Y_{j 0}-\sum_{i=1}^{N} p_{i}^{*} M_{j 0}^{i}$, where $\left(P_{j}^{y}\right)^{*}$ and $p_{j}^{*}$ represent the steady state values of the producer and user prices. 
The growth rate of aggregate value added is defined as a weighted average of the growth rate of sectoral value added, with the weights being equal to the average of the $j^{\text {th }}$ sector's share of nominal value added:

$$
\Delta V_{t}=\frac{1}{2} \sum_{j=1}^{N}\left(s_{j, t}+s_{j, t-1}\right) \Delta V_{j t}, s_{j t}=\frac{p_{j t}^{v} V_{j t}}{p_{t}^{v} V_{t}} .
$$

\subsection{Welfare costs computation}

We compute the welfare costs for a finite horizon $T$, and focus on the consumption component of the utility function. Our measure of the welfare costs is the percentage change in annual consumption $\phi$ from the no policy deterministic steady state needed to achieve the same level of utility in no policy and no uncertainty scenario as the expected level of utility in the case of a particular policy and specific types of productivity shocks.

Deterministic case Let $\bar{c}$ denote the no policy deterministic steady state of consumption. The welfare costs are computed by solving the following equality for the value of $\phi$ :

$$
\sum_{t=0}^{T} \beta^{t} \ln [\bar{c}(1-\phi)]=\sum_{t=0}^{T} \beta^{t} \ln \left[c_{t}(\text { policy })\right] \equiv U_{T}(\text { policy }),
$$

where $c_{t}$ denotes the simulated path of consumption in the model with the emissions controls. To simplify, $\phi$ is determined as

$$
\ln (1-\phi)=\frac{1-\beta}{1-\beta^{T+1}}\left[U_{T}(\text { policy })-\sum_{t=0}^{T} \beta^{t} \ln \bar{c}\right] .
$$

In computing the statistics for the 55-100 periods, we treat the period 55 at the initial period of the model.

Stochastic case The welfare costs in the stochastic case are determined by equating the utility in the no policy deterministic steady state with the expected utility:

$$
\sum_{t=0}^{T} \beta^{t} \ln [\bar{c}(1-\phi)]=E\left[\sum_{t=0}^{T} \beta^{t} \ln \left[c_{t}(\text { policy })\right]\right] .
$$

The welfare cost $\phi$ is determined as

$$
\ln (1-\phi)=\frac{1-\beta}{1-\beta^{T+1}}\left[\frac{1}{N r e p} \sum_{n=0}^{N r e p} U_{T}(\text { policy }, n)-\sum_{t=0}^{T} \beta^{t} \ln \bar{c}\right]
$$

where $U_{T}($ policy,$n)=\sum_{t=0}^{T} \beta^{t} \ln \left[c_{t}(\right.$ policy,$\left.n)\right]$ corresponds to the level of utility for the $n^{t h}$ replication of the economy with the emissions policy. 